\title{
Microglial-derived microparticles mediate neuroinflammation after traumatic brain injury
}

Alok Kumar ${ }^{1,2}$, Bogdan A. Stoica 1,2, David J. Loane ${ }^{1,2}$, Ming Yang ${ }^{3}$, Gelareh Abulwerdi,2, Niaz Khan ${ }^{1,2}$, Asit Kumar ${ }^{1,2}$, Stephen R. Thom ${ }^{3}$ and Alan I. Faden ${ }^{1,2^{*}}$

\begin{abstract}
Background: Local and systemic inflammatory responses are initiated early after traumatic brain injury (TBI), and may play a key role in the secondary injury processes resulting in neuronal loss and neurological deficits. However, the mechanisms responsible for the rapid expansion of neuroinflammation and its long-term progression have yet to be elucidated. Here, we investigate the role of microparticles (MP), a member of the extracellular vesicle family, in the exchange of pro-inflammatory molecules between brain immune cells, as well as their transfer to the systemic circulation, as key pathways of inflammation propagation following brain trauma.

Methods: Adult male C57BL/6 mice were subjected to controlled cortical impact TBI for $24 \mathrm{~h}$, and enriched MP were isolated in the blood, while neuroinflammation was assessed in the TBI cortex. MP were characterized by flow cytometry, and MP content was assayed using gene and protein markers for pro-inflammatory mediators. Enriched MP co-cultured with BV2 or primary microglial cells were used for immune propagation assays. Enriched MP from BV2 microglia or CD11b-positive microglia from the TBI brain were stereotactically injected into the cortex of uninjured mice to evaluate MP-related seeding of neuroinflammation in vivo.

Results: As the neuroinflammatory response is developing in the brain after TBI, microglial-derived MP are released into the circulation. Circulating enriched MP from the TBI animals can activate microglia in vitro. Lipopolysaccharide stimulation increases MP release from microglia in vitro and enhances their content of pro-inflammatory mediators, interleukin-1 $\beta$ and microRNA-155. Enriched MP from activated microglia in vitro or CD11b-isolated microglia/ macrophage from the TBI brain ex vivo are sufficient to initiate neuroinflammation following their injection into the cortex of naïve (uninjured) animals.

Conclusions: These data provide further insights into the mechanisms underlying the development and dissemination of neuroinflammation after TBI. MP loaded with pro-inflammatory molecules initially released by microglia following trauma can activate additional microglia that may contribute to progressive neuroinflammatory response in the injured brain, as well as stimulate systemic immune responses. Due to their ability to independently initiate inflammatory responses, MP derived from activated microglia may provide a potential therapeutic target for other neurological disorders in which neuroinflammation may be a contributing factor.
\end{abstract}

Keywords: Microparticles, Microglia, Neuroinflammation, Traumatic brain injury, Interleukin-1 $\beta$, miR-155

\footnotetext{
* Correspondence: afaden@anes.umm.edu

${ }^{1}$ Department of Anesthesiology, University of Maryland School of Medicine,

Baltimore, MD, USA

${ }^{2}$ Shock, Trauma and Anesthesiology Research (STAR) Center, University of

Maryland School of Medicine, Health Sciences Facility II (HSFII), \#S247 20

Penn Street, Baltimore, MD 21201, USA

Full list of author information is available at the end of the article
} 


\section{Background}

Microparticles (MP; also called microvesicles), a type of extracellular vesicle, are small membrane-bound bodies shed from the plasma membrane and released by cells during activation or cell death [1]. They are composed of the plasma membrane along with a limited amount of cytoplasm and measure 100 to $1000 \mathrm{~nm}$ in diameter [2]. MP are enriched in the lipid microdomains, where cholesterol, phospholipids, and receptors are clustered [3], and are distinguished from other extracellular vesicles such as exosomes (30-100 nm; endosomal origin) and apoptotic bodies (1000-2000 nm) [1]. MP can be released from virtually all cell types in the brain and contain molecular signals in the form of non-secreted proteins and DNA/RNA/microRNA (miR) molecules that may be involved in cell-to-cell communication during neurodevelopment and synaptic physiology [4]. MP and other extracellular vesicles have also been implicated in the development and progression of various neurological diseases [4]. For example, in transmissible spongiform encephalopathy accumulation and cell-tocell transmission of infectious prion proteins $\left(\operatorname{Pr} \mathrm{P}^{\mathrm{sc}}\right)$, extracellular vesicles are a key mechanism of prion disease propagation $[5,6]$. In amyotrophic lateral sclerosis, accumulating evidence indicates that a mechanism for the progressive accumulation of misfolded mutant form of superoxide dismutase 1 (SOD1) is cell-to-cell propagation of SOD1 within the brain via extracellular vesicles that extend the range and toxicity during disease $[7,8]$. Similar mechanisms are thought to contribute to neurotoxic amyloid- $\beta$ formation in Alzheimer's disease models [9-11]; however, these data are more controversial given that other studies have shown that exosome-associated amyloid- $\beta$ are neuroprotective $[12,13]$.

Traumatic brain injury (TBI) causes cell death and neurologic dysfunction through secondary injury mechanisms characterized by edema, neuronal cell death, glial activation, and infiltration of peripheral immune cells, among others [14]. The inflammatory response to TBI is highly complex and includes rapid proliferation and migration of resident microglia to the site of injury in response to damage-associated molecular patterns (DAMPs) and other factors released by injured tissue [15], as well as by infiltration of neutrophils and inflammatory monocyte subsets that contribute to the injury milieu [16]. If the immune response is unable to resolve effectively, or becomes dysregulated after TBI, it can contribute to chronic neurodegeneration, due to chronic activation of neurotoxic microglia [17]. Elevated levels of MP have been reported in the cerebrospinal fluid of TBI patients [18], and circulating MP derived from endothelial cells, platelets, and leukocytes have been measured acutely after severe isolated TBI [19]. These include cerebral endothelium-derived MP release following focal contusion injury [20] as well as neuronal- and astroglialderived MP release following mixed contusion and diffuse axonal injury [21].

Given the increasingly recognized role for neuroinflammation in tissue damage after TBI, we examined whether posttraumatic circulating MP released after injury could be derived from microglia, as well as potential mechanisms of microglial MP involvement in cell-to-cell communication in the brain following trauma. We hypothesized that MP released by microglia contain proinflammatory molecules that contribute to the spread of brain inflammation. We used flow cytometry to identify the origin of brain-specific immune-related MP in the circulation following controlled cortical impact in mice. To investigate immunogenic properties of microglial-derived MP, we used BV2 microglia and primary microglial cell culture models. Finally, to demonstrate cell-to-cell propagation of neuroinflammatory mechanisms within the brain, we injected enriched MP derived from microglia isolated from TBI cortex or lipopolysaccharide (LPS)stimulated microglia into the cortex of uninjured mice.

\section{Methods \\ Animals}

Studies were performed using C57BL/6 adult male mice (10-12 weeks old, 22-26 g). The mice were housed in the Animal Care facility at the University of Maryland School of Medicine under a 12-h light-dark cycle with ad libitum access to food and water. All surgical procedures were carried out in accordance with protocols approved by the Institutional Animal Care and Use Committee (IACUC) at the University of Maryland School of Medicine.

\section{Controlled cortical impact}

Our custom-designed controlled cortical impact (CCI) TBI device consists of a microprocessor-controlled pneumatic impactor with a $3.5-\mathrm{mm}$ diameter tip. Mice were anesthetized with isoflurane evaporated in a gas mixture containing $70 \% \mathrm{~N}_{2} \mathrm{O}$ and $30 \% \mathrm{O}_{2}$ and administered through a nose mask (induction at $4 \%$ and maintenance at 2\%). Depth of anesthesia was assessed by monitoring respiration rate and pedal withdrawal reflexes. Mice were placed on a heated pad, and core body temperature was maintained at $37{ }^{\circ} \mathrm{C}$. The head was mounted in a stereotaxic frame, and the surgical site was clipped and cleaned with Nolvasan and ethanol scrubs. A $10-\mathrm{mm}$ midline incision was made over the skull, the skin and fascia were reflected, and a 5-mm craniotomy was made on the central aspect of the left parietal bone. The impounder tip of the injury device was then extended to its full stroke distance $(44 \mathrm{~mm})$, positioned to the surface of the exposed dura, and reset to impact the cortical surface. Moderate-level TBI was induced using an impactor velocity of $6 \mathrm{~m} / \mathrm{s}$ and deformation depth of 
$2 \mathrm{~mm}$ as previously described [22]. After injury, the incision was closed with interrupted 6-0 silk sutures, anesthesia was terminated, and the animal was placed into a heated cage to maintain normal core temperature for 45 min post-injury. Sham animals underwent the same procedure as TBI mice except for the impact.

\section{Study 1}

Sham $(n=6)$ and TBI $(n=6)$ of C57BL/6J mice were anesthetized $(100 \mathrm{mg} / \mathrm{kg}$ sodium pentobarbital, I.P.) at $24 \mathrm{~h}$ post-injury, and blood was collected in heparinized syringes by aortic puncture for blood MP analysis. Ipsilateral cortical tissue was rapidly dissected and snapfrozen on liquid nitrogen for RNA extraction

\section{Study 2}

Sham $(n=5)$ and TBI $(n=5)$ of C57BL/6J mice were anesthetized $(100 \mathrm{mg} / \mathrm{kg}$ sodium pentobarbital, I.P.) at 7 days post-injury and transcardially perfused with icecold $0.9 \%$ saline $(100 \mathrm{ml})$. Ipsilateral cortical and hippocampal tissues were rapidly dissected and processed for CD11b-positive selection and MP isolation.

\section{Enriched MP isolation and analysis}

Mice were anesthetized $(100 \mathrm{mg} / \mathrm{kg}$ sodium pentobarbital, I.P.), and blood was collected in heparinized syringes by aortic puncture. Blood was immediately combined with fixative $(100 \mu \mathrm{l} / \mathrm{ml}$ Caltag Reagent A fixation medium, Invitrogen, Carlsbad, CA) to diminish ex vivo microparticle (MP) aggregation. All reagents and solutions used for MP analysis were sterile and filtered (0.1- $\mu \mathrm{m}$ filter). Heparinized blood was centrifuged for $5 \mathrm{~min}$ at $1500 \times \mathrm{g}$, and supernatant was centrifuged at $15,000 \times g$ for $30 \mathrm{~min}$ to pellet platelets and other cell debris [23]. Blood supernatants were used to collect total blood MP $(\sim 250 \mu \mathrm{l})$ that were purified by adding PBS $(4 \mathrm{ml})$ and centrifuged at $100,000 \times \mathrm{g}$ for $60 \mathrm{~min}$ at $4{ }^{\circ} \mathrm{C}$ as previously described [23-30]. In each experiment, flow cytometry in combination with microbead standards ranging in size from 300 to $3000 \mathrm{~nm}$ was used to characterize MP size. MP were distinguished from larger (apoptotic body; $>1000 \mathrm{~nm}$ ) and smaller (exosomes; $<100 \mathrm{~nm}$ ) vesicles based on size (SSC), and their phenotype was confirmed using the unique MP surface marker, annexin $\mathrm{V}$ (details below; see Fig. 1a). In parallel experiments, equal numbers of circulating MP from sham and TBI mice $\left(8 \times 10^{5} \mathrm{MP}\right)$ were resuspended in $100 \mu \mathrm{l}$ serum-free DMEM media and co-cultured with BV2 microglia $\left(2 \times 10^{4}\right.$ cells/well) for $24 \mathrm{~h}$ at $37{ }^{\circ} \mathrm{C}$ and at $5 \% \mathrm{CO}_{2}$ prior to cell extraction for markers of microglial activation. The enriched MP population obtained using this protocol may also contain other types of extracellular vesicles such as exosomes.

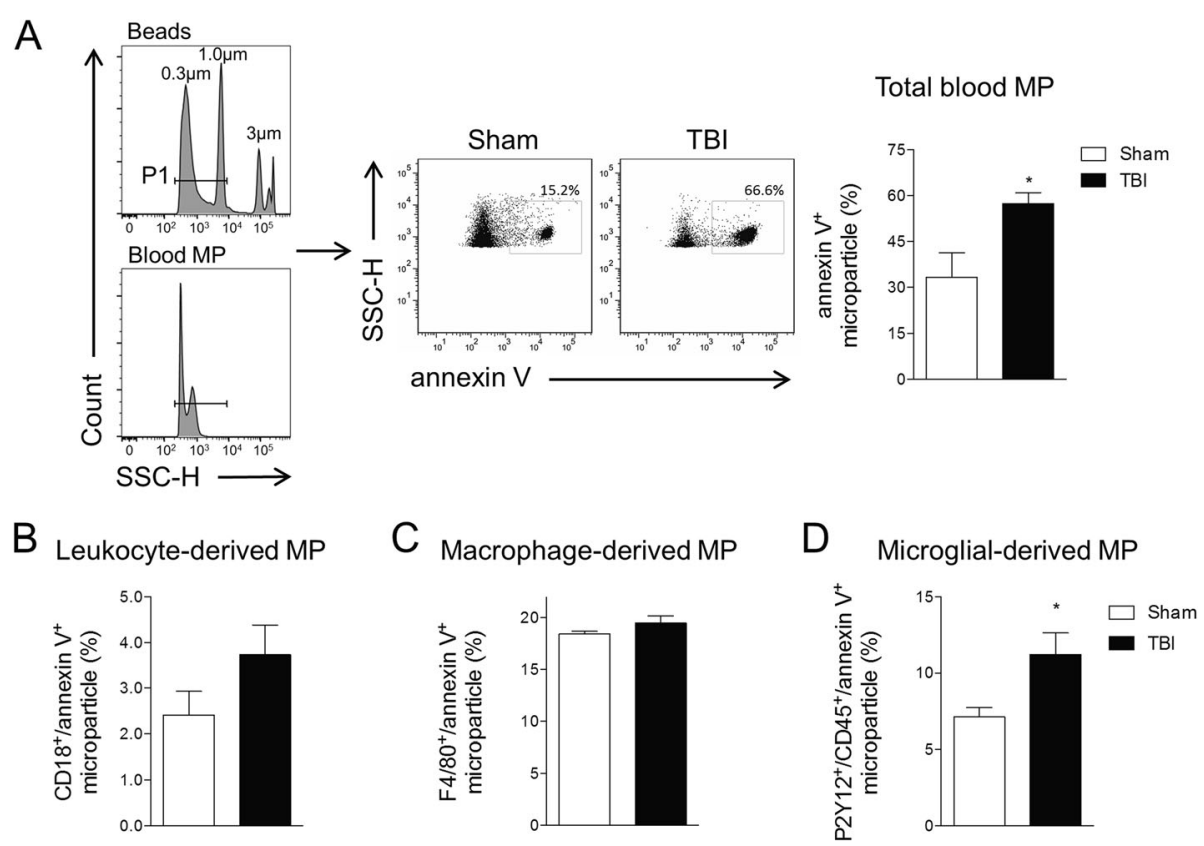

Fig. 1 Microglial-derived MP are increased in the blood following TBI. Flow cytometry analysis of enriched MP in the blood from sham and TBI mice at $24 \mathrm{~h}$ post-injury. a Representation of gating strategy used to characterize MP using SSC-H and standard microbeads (300- to 1000-nm diameter). Standard microbeads (P1 gated population) were used as an internal control to determine the size of MP in the blood, and annexin V staining confirmed MP characteristics. At $24 \mathrm{~h}$ post-injury, total blood MP is increased in TBI mice compared with sham-injured mice. $\mathbf{b}$ Measurements of leukocyte-derived (CD18), macrophage-derived (F4/80), and microglial-derived (P2Y12/CD45) MP in the blood from sham and TBI mice at $24 \mathrm{~h}$ post-injury. Microglial-derived MP are significantly increased in TBI mice when compared with sham-injured mice ( ${ }^{*} p<0.5$ vs sham; Student's $t$ test; $n=6 /$ group). Bars represent mean \pm standard error of the mean (S.E.M.). Data represent results of three independent experiments 
Total and cell-derived MP were identified by flow cytometry using an eight-color, triple-laser MACSQuant Analyzer (Miltenyi Biotec, Auburn, CA). MACSQuant was calibrated every other day with calibration beads (Miltenyi Biotec, Auburn, CA), and forward and side scatters were set at logarithmic gain. Photomultiplier tube voltage and triggers were optimized to detect submicron-sized particles. Microbeads of different diameters (0.3 $\mu \mathrm{m}$ (Sigma; LB3), $1.09 \mu \mathrm{m}$ (Spherotech, Lake Forest, IL; BCP-10-5), and $3.0 \mu \mathrm{m}$ (Spherotech, Lake Forest, IL; BP-30-5)) were used to set initial parameters and to confirm MP characteristics in each experiment. To reduce small particle contaminants, all reagents and solutions used for MP analysis were sterile and filtered (0.1- $\mu \mathrm{m}$ filter; EMD Millipore, Billerica, MA) before use. The expression of phosphatidylserine (PS) on MP was detected using an anti-annexin V (FITC or APC) (1:50, BD Biosciences PharMingen, catalog no: 556419) in annexin buffer $\left(5 \mathrm{mM} \mathrm{KCl}, 1 \mathrm{mM} \mathrm{MgCl}_{2}, 136 \mathrm{mM}\right.$ $\mathrm{NaCl}, 2 \mathrm{mM} \mathrm{CaCl}, 1 \% \mathrm{BSA} ; \mathrm{pH}$ 7.4). MP were incubated with antibodies for $30 \mathrm{~min}$ at room temperature (RT) in the dark. Annexin buffer $(150 \mu \mathrm{l})$ was added to each sample prior to MACSQuant analysis. Truenegative controls were established by a fluorescenceminus-one analysis and using isotype-matched irrelevant antibodies at the same concentration and under the same conditions. Annexin V-positive particles with diameters from 300 to $1000 \mathrm{~nm}$ were defined as MP. Blood MP were further characterized by double labeling with specific cell-specific antibodies: leukocytes (anti-CD18 (PE); 1:50, Biolegend; catalog no: 101408) and monocyte/macrophages (anti-F4/80 (APC); 1:50, Thermo Fisher, catalog no: MF48005). Microglial staining was performed using anti-P2Y12 (1:1000, AnaSpec Inc., Fremont, CA) and antiCD45-PerCP (1:10, Miltenyi Biotec, Auburn, CA) as follows: MP were incubated with anti-P2Y12 in annexin buffer for $1 \mathrm{~h}$ at RT, washed and incubated with Alexa Fluor 488 goat anti-rabbit secondary antibodies (1:500; Life Technologies) for $30 \mathrm{~min}$, washed and further incubated with pre-conjugated anti-CD45 for $30 \mathrm{~min}$ at RT, and washed in annexin buffer prior to analysis by flow cytometry. FlowJo software (Vx; Tree Star, Inc., Ashland, OR) was used for analysis, and data are presented as percent of annexin V-positive MP in the MP gate as set by microbeads, unless otherwise specified.

\section{In vitro MP analysis}

BV2 microglia (murine microglial cell line) were cultured in DMEM (Invitrogen, Carlsbad, CA) supplemented with $10 \%$ fetal equine serum (HyClone, Logan, UT), and 1\% penicillin and streptomycin (Invitrogen) at $37{ }^{\circ} \mathrm{C}$ with $5 \% \mathrm{CO}_{2}$. DMEM media was filtered using $0.1-\mu \mathrm{m}$ filters. BV2 microglia were seeded at a density of $0.6 \times 10^{6}$ in $60-\mathrm{mm}$ dishes and stimulated with lipopolysaccharide (LPS, $20 \mathrm{ng} / \mathrm{ml}$; Sigma-Aldrich) or control media for $24 \mathrm{~h}$. MP released into conditioned BV2 microglial media were characterized using a MACSQuant flow cytometer (Miltenyi Biotec, San Diego, CA) analysis as described before. In parallel experiments, MP in conditioned media were pelleted by centrifugation as described before and MP-enriched pellets were either resuspended in RIPA buffer (Teknova, Hollister, CA) for Western blotting or extracted using TRIzol reagent (Invitrogen) for RNA analysis. In another experiment, BV2 microglia cells were stained with $1 \mu \mathrm{M}$ calcein $\mathrm{AM}$ (Invitrogen) in DMEM for $30 \mathrm{~min}$ at $37^{\circ} \mathrm{C}$ and then stimulated with LPS $(20 \mathrm{ng} / \mathrm{ml})$ for $24 \mathrm{~h}$. Calcein AMlabeled MP were isolated from conditioned media by centrifugation at $100,000 \times g$ for $60 \mathrm{~min}$ at $4{ }^{\circ} \mathrm{C}$ [23-30] and were stained with anti-annexin V (APC) (1:50, BD Biosciences PharMingen, catalog no: 550474) for MP characterization by flow cytometry as described before.

Levels of endotoxin (LPS) in pelleted MP from control and LPS-stimulated BV2 microglia were determined using a LAL Chromogenic Endotoxin assay (Thermo Fisher Scientific, MA, USA) as per manufacturer's instructions. A standard curve was used to determine the concentration of endotoxin in each sample. Endotoxin levels are expressed as endotoxin unit per milliliter $(\mathrm{EU} / \mathrm{ml})$.

\section{MP co-culture studies}

BV2 microglia were seeded at a density of $0.6 \times 10^{6}$ in $60-\mathrm{mm}$ dishes and stimulated with LPS $(20 \mathrm{ng} / \mathrm{ml})$ or control media for $24 \mathrm{~h}$. MP released into conditioned BV2 microglial media were isolated by centrifugation as described before. Control and LPS-stimulated MP (total $\left.8 \times 10^{5} \mathrm{MP}\right)$ were co-cultured with BV2 microglia $(2 \times$ $10^{4} / 96$ well $)$ or primary microglia $\left(1 \times 10^{5} / 96\right.$ well $)$ that were obtained from postnatal day 1 C57BL/6 mouse pups as previously described [31] for $24 \mathrm{~h}$ at $37{ }^{\circ} \mathrm{C}$ and at $5 \% \mathrm{CO}_{2}$ prior to cell extraction using TRIzol reagent (Invitrogen) to assess markers of microglial activation.

\section{MP isolation from CD11b-positive cells from the sham and $\mathrm{TBI}$ cortex}

Magnetic bead-conjugated anti-CD11b and MACS separation technology (Miltenyi Biotec, Auburn, CA) was used to isolate microglia/macrophages from sham and TBI brain tissue of C57BL/6J mice at 7 days post-injury ( $n=5$ /group; study 2 above). Briefly, ipsilateral cortical and hippocampal tissues were rapidly microdissected, and a single cell suspension was prepared using enzymatic digestion (Neural Tissue Dissociation Kit; Miltenyi Biotec) in combination with a gentle MACS dissociator. Myelin was removed using Myelin Removal Beads II and LS columns (Miltenyi Biotec), and the cells were incubated with anti-CD11b microbeads (Miltenyi Biotec) and loaded onto MS columns (Miltenyi Biotec) placed in the 
magnetic field of a MACS separator. The negative fraction (flow through) was collected, and the column was washed three times with MACS buffer (Miltenyi Biotech). CD11b-positive cells were eluted by removing the magnetic field, resulting in the isolation of approximately 93\% viable CD11b-positive cells from sham and TBI mice [32]. Expression level of CD11b-positive selected cells (MFI) was quantified by flow cytometry using anti-CD11b (APC) (1:50; Miltenyi Biotech, catalog no: 130-091-241). CD11b-positive cells were subsequently seeded at $1 \times 10^{5}$ cells/well in a 96-well plate in DMEM-F12 containing $10 \%$ fetal calf serum and incubated at $37{ }^{\circ} \mathrm{C}$ under $5 \% \mathrm{CO}_{2}$ for $24 \mathrm{~h}$. Ex vivo-secreted MP from sham and TBI CD11b-positive cells were collected from condition media by ultra centrifugation as described before.

\section{Intracortical injection of enriched MP Study 1}

Enriched MP were isolated from conditioned media of control and LPS (20 ng/ml)-stimulated BV2 microglia as described before. To neutralize the effects of MP, additional groups of control and LPS-stimulated MP were incubated with polyethylene glycol telomere B (PEG-TB; $6 \mu \mathrm{l}$ per $100 \mu \mathrm{l}$ media) for $1 \mathrm{~h}$ at RT as previously described [25]. MP were resuspended in $100 \mu \mathrm{l}$ artificial CSF (Na 150, K 3.0, Ca 1.4, Mg 0.8, P 1.0, Cl 155 (mM); Harvard Apparatus, Holliston, MA, catalog no: 597316 ), and $1 \mu \mathrm{l}$ (total $8 \times 10^{3} \mathrm{MP}$ ) was injected intracortically into C57BL/6 mice $(n=6)$ at stereotactic coordinates of $2.0 \mathrm{~mm}$ anteroposterior, $1.0 \mathrm{~mm}$ mediolateral to the bregma, and $1.0 \mathrm{~mm}$ below the pia using a 33-gauge sharp needle attached to a 10- $\mu$ l Hamilton syringe (Hamilton Medical, Reno, NV, USA) and an injection rate of $1 \mu \mathrm{l} / 10 \mathrm{~min}$. The needle remained in situ for $5 \mathrm{~min}$ to prevent backflow before being withdrawn slowly over $10 \mathrm{~min}$. Twenty-four hours later, the mice were euthanized and cortical tissue was collected using TRIzol reagent (Invitrogen) to assess markers of cortical neuroinflammation.

\section{Study 2}

MP were isolated from conditioned media of control and LPS $(20 \mathrm{ng} / \mathrm{ml})$-stimulated BV2 microglia as described before, and $1 \mu \mathrm{l} \mathrm{MP}$ (total $8 \times 10^{3} \mathrm{MP}$ ) were injected intracortically into C57BL/6 mice $(n=4)$ as described in study 1 above. Seven days later, mice were euthanized and the brains were removed to assess markers of microglial activation using histology.

\section{Study 3}

MP isolated from culture media of CD11b-positive cells from sham and TBI brain as described above were resuspended in $100 \mu \mathrm{l}$ artificial CSF (Harvard Apparatus), and
$1 \mu \mathrm{l} \mathrm{MP}$ (total $8 \times 10^{3} \mathrm{MP}$ ) were injected intracortically into C57BL/6 mice $(n=4)$ as described above. Twentyfour hours later, the mice were euthanized and cortical tissue was collected using TRIzol reagent (Invitrogen) to assess markers of cortical neuroinflammation.

\section{Real-time PCR}

Total RNA including miR was extracted from snapfrozen tissue, cells, or enriched MP, using a miRNeasy mini isolation kit (Qiagen, Valencia, CA). Complementary DNA (cDNA) synthesis was performed on $1 \mu \mathrm{g}$ of total RNA using a Verso cDNA RT kit (Thermo Scientific, Pittsburg, PA), as per manufacturer's instructions. For messenger RNA (mRNA) analysis, real-time PCR was performed using TaqMan gene expression assays on an ABI 7900 HT FAST Real-Time PCR machine (Applied Biosystems). Gene expression was calculated relative to the endogenous control sample (GAPDH) to determine relative expression values $\left(2^{-\Delta \Delta \mathrm{Ct}}\right.$, where $\mathrm{Ct}$ is the threshold cycle). For miR analysis, a total of $10 \mathrm{ng}$ of total RNA was reverse transcribed using TaqMan miRNA Reverse Transcription Kit (Applied Biosystems) with miR-specific primer of miR-155 and control U6. Reverse transcription reaction products $(1.5 \mu \mathrm{l})$ were used for qPCR as described above. Following real-time PCR, miR expression was calculated relative to the endogenous control sample (U6) to determine relative expression values $\left(2^{-\Delta \Delta C t}\right.$, where $\mathrm{Ct}$ is the threshold cycle).

\section{Western blotting}

Proteins were extracted using RIPA buffer (Teknova, Hollister, CA), equalized, and loaded equally onto $5-20 \%$ gradient gels for SDS PAGE (Bio-Rad; Hercules, CA). Proteins were transferred onto nitrocellulose membranes and blocked overnight in 5\% milk in 1x PBS containing $0.01 \%$ Tween-20 (PBS-T). The membrane was incubated in rabbit anti-interleukin-1 $\beta$ (anti-IL-1 $\beta$ ) (1:1000; Cell Signaling, catalog no: sc-7884) and mouse anti- $\beta$-actin (1:20,000; Sigma, catalog no: A1978) overnight at $4{ }^{\circ} \mathrm{C}$, then washed three times in PBS-T for $5 \mathrm{~min}$, and incubated in appropriate HRP-conjugated secondary antibodies (Jackson Immuno Research Laboratories, West Grove, PA) for $1 \mathrm{~h}$ at RT. Membranes were washed three times in PBS-T, and proteins were visualized using Super Signal West Dura Extended Duration Substrate (Thermo Scientific, Rockford, IL). Chemiluminescence was captured using ChemiDoc TM XRS+ System (Bio-Rad; Hercules, CA), and protein bands were quantified by densitometric analysis using Image J $(\mathrm{NIH}$, Bethesda, $\mathrm{MD})$. The data reflects the intensity of the target protein band normalized based on the intensity of the endogenous control for each sample (expressed in arbitrary units). 
Protein from cells was normalized to $\beta$-actin, and protein from MP was normalized to Ponceau-S.

\section{Immunofluorescence imaging}

Twenty-micrometer coronal brain sections from $-1.70 \mathrm{~mm}$ from the bregma were selected, and standard immunostaining techniques were employed. Briefly, 20- $\mu \mathrm{m}$ sections were washed three times with $1 \mathrm{x}$ PBS, blocked for $1 \mathrm{~h}$ in goat serum containing $0.4 \%$ Triton X-100, and incubated overnight at $4{ }^{\circ} \mathrm{C}$ with primary antibody (rabbit anti-P2Y12 (1:1000, AnaSpec Inc., Fremont, CA; catalog no: AS55043A), rabbit anti-Iba-1 (1:200; Wako Chemicals, Richmond, VA; catalog no: 019-197)). Sections were washed three times with $1 \mathrm{x}$ PBS and incubated with appropriate Alexa Fluor-conjugated secondary antibodies (Life Technologies) for $2 \mathrm{~h}$ at RT. Sections were washed three times with 1x PBS, counterstained with 4',6-diamidino-2-phenylindole (DAPI; $1 \mu \mathrm{g} / \mathrm{ml}$, Sigma), and mounted with glass cover slips using Hydromount solution (National Diagnostics, Atlanta, GA). Images were acquired using a fluorescent Nikon Ti-E inverted microscope, at $\times 10$ (Plan Apo $10 \times$ NA 0.45 ) or $\times 20$ (Plan APO $20 \times$ NA 0.75 ) magnification. Exposure times were kept constant for all sections in each experiment. All images were quantified using Nikon NDElements Software (AR 4.20.01). 6000-10,000 positive areas were quantified per mouse per experiment, and expression levels were expressed as binary area per region of interest $(\mathrm{ROI}) \times 10^{6}$.

\section{Assessment of microglial morphology}

Neurolucida software (MBF Biosciences, Williston, VT) was used to quantify cell body area and ramification length of P2Y12-positive microglia in the cortex, hippocampus, and thalamus of enriched MP intracortical injected mice as previously described [33]. Immunostained microglia were outlined using the live image setting so that the width of the ramified branches could be traced while focusing on the section. Cell bodies were outlined using the contour tool followed by tracing of the individual ramification using the dendrite line tool. Microglial ramification length is expressed in micrometers,, and cell body area is expressed in square millimeters.

\section{Statistical analysis}

Randomization and blinding protocols were employed, and individuals performing in vitro and in vivo analysis were blinded to isolated MP groups. Quantitative data were expressed as mean \pm standard errors of the mean (S.E.M.). qPCR and flow cytometry data were analyzed by one-way ANOVA, followed by post hoc adjustments using a Student-Newman-Keuls test. Remaining data were analyzed using Student's $t$ test. Statistical analyses were performed using GraphPad Prism Program, Version 3.02 for Windows (GraphPad
Software, San Diego, CA, USA). A $p<0.05$ was considered statistically significant.

\section{Results \\ Microglia-derived microparticles are released into circulation following TBI}

C57BL/6 male mice were subjected to TBI (moderatelevel CCI) or sham surgery, and $24 \mathrm{~h}$ later, animals were euthanized and blood was collected for MP isolation and characterization. Ipsilateral cortical tissue was also collected to assess markers of brain inflammation. MP in blood were measured by flow cytometry for annexin $\mathrm{V}$, which binds the externalized phosphatidylserine (PS) present on the surface of MP. To exclude the presence of annexin V-positive apoptotic bodies (>1000 $\mathrm{nm}$ ) and smaller exosomes $(<100 \mathrm{~nm})$ in the sample, microbead standards $(300,1000$, and $3000 \mathrm{~nm}$ ) were used to gate on MP (MP gate set between 300 and $1000 \mathrm{~nm}$ ) (Fig. 1a). There was a significant increase in annexin V-positive MP in the blood of TBI mice when compared to shaminjured controls $(p<0.05$; Fig. 1a).

We next evaluated the origin of the circulating MP based on unique markers derived from parental cells. P2Y12/CD45-positive MP (microglial derived) were significantly increased in the circulation when compared to sham-injured control levels $(p<0.05 ;$ Fig. 1b). The CD18-positive MP (leukocyte derived) increase after TBI did not reach statistical significance, and TBI did not increase levels of F4/80-positive MP (monocyte derived) in the circulation at $24 \mathrm{~h}$ post-injury. These data indicate that microglial-derived MP are released into the circulation after moderate-level TBI.

Assessment of injured cortical tissue revealed a robust neuroinflammatory response to $\mathrm{TBI}$, with increased mRNA expression of markers of microglial activation and the induction of pro-inflammatory cytokines and chemokines. Specifically, TBI resulted in a significant increase in mRNA for CD11b $(p<0.01)$, nitric oxide synthase 2 (NOS2, $\mathrm{p}<0.01)$, interleukin-1 $\beta$ (IL-1 $\beta, p<0.05)$, tumor necrosis factor-alpha (TNF- $\alpha, \mathrm{p}<0.001$ ), C-C motif chemokine ligand 2 (CCL2, $\mathrm{p}<0.01$ ), interleukin-6 (IL-6, $p$ $<0.001$ ), pro-inflammatory microRNA-155 (miR-155, $p<$ $0.05)$, and the purinergic receptor P2X7 $(p<0.05)$ when compared to the sham-injured group (Fig. 2a). Histological assessment of P2Y12 expression on microglia in the ipsilateral cortex revealed that the following moderate TBI P2Y12-positive microglia transform from a ramified morphological state to an activated state that withdrew branched processes to form thick bundles around highly enlarged cell bodies (Fig. 2b). Further, Neurolucida reconstruction analysis of P2Y12-positive cells demonstrated that ramification length was significantly decreased $(p<0.01)$ and cell body area was 

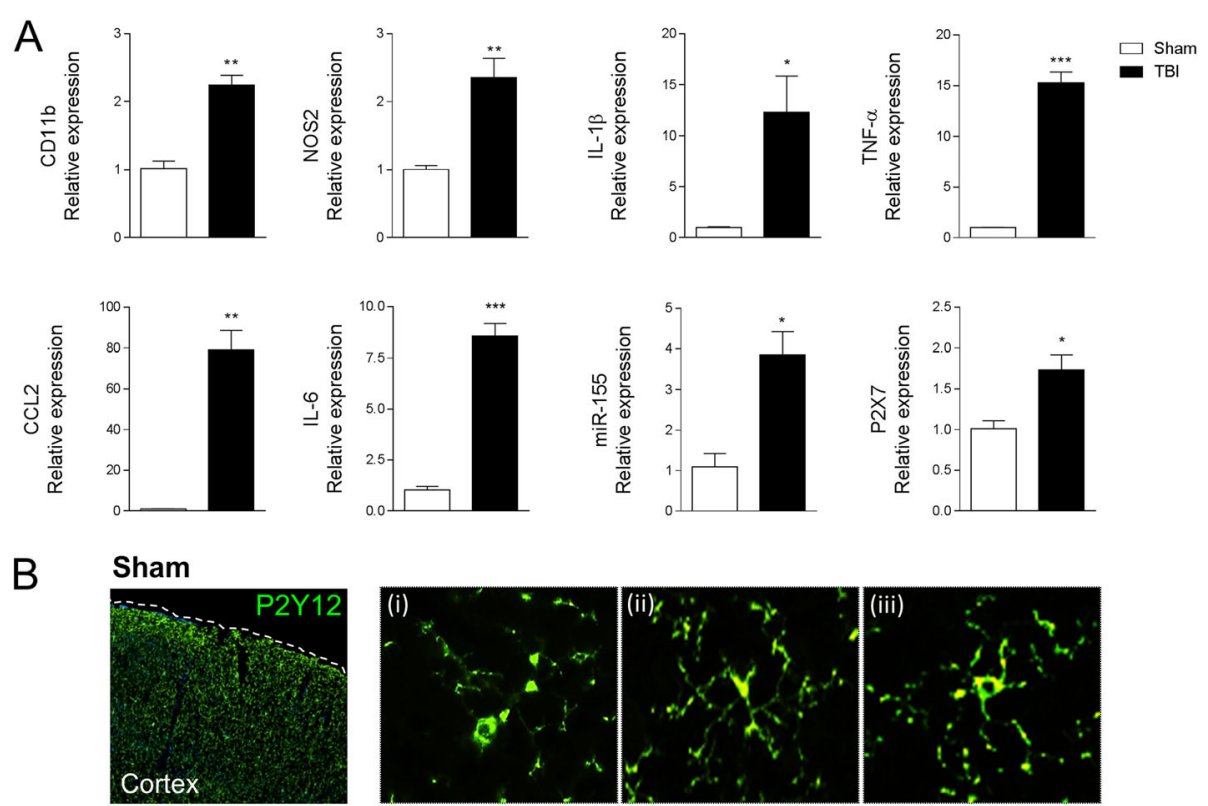

\section{TBI}
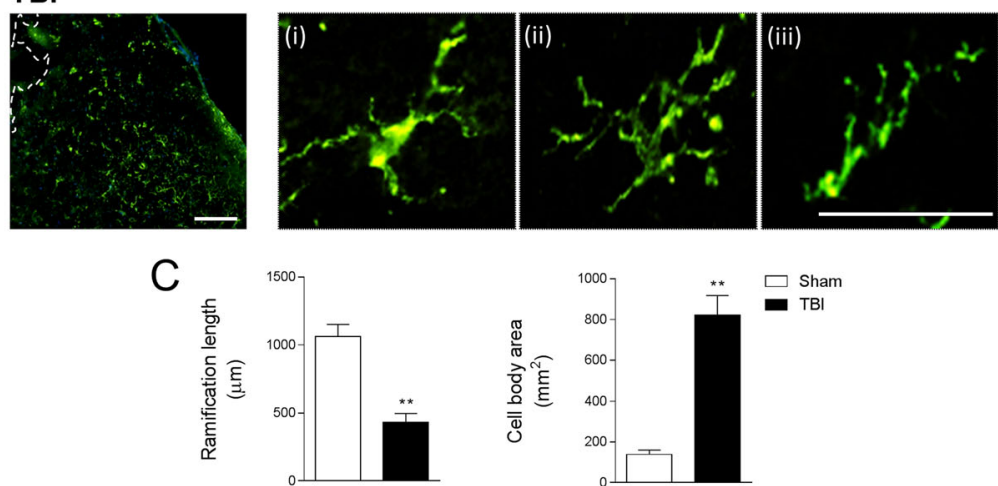

Fig. 2 Microglial activation in the TBI brain at $24 \mathrm{~h}$ post-injury. a Gene expression analysis of microglia activation in the cortex of sham and TBI mice at $24 \mathrm{~h}$ post-injury. Microglial receptors (CD11b, P2X7) and pro-inflammatory mediators (NOS2, IL-1 $\beta$, TNF-a, CCL2, IL-6, and miR-155) were significantly increased in the injured cortex at $24 \mathrm{~h}$ post-injury $\left({ }^{*} p<0.05,{ }^{* *} p<0.01\right.$, and ${ }^{* *} p<0.001$ vs sham-injured; Student's $t$ test; $n=6 /$ group). b Immunofluorescence imaging for P2Y12-positive microglia in the cortex of sham and TBI mice at $24 \mathrm{~h}$ post-injury. Following TBI P2Y12-positive microglia transformed from a ramified morphology in sham to activated morphology displaying enlarged cell body, and thicker, and shorter, projections. Representative images taken at $-2.06 \mathrm{~mm}$ from the bregma. Scale bar $=50 \mu \mathrm{m}$. c Morphological analysis of P2Y12-positive microglia using 3D-reconstruction Neurolucida software. When compared to sham-injured controls, P2Y12-positive microglia in the TBI cortex had reduced ramification length ( ${ }^{* *} p<0.01$; Student's $t$ test) and an enlarged cell body area $\left({ }^{* *} p<0.01\right.$; Student's $t$ test; $n=6 /$ group). Bars represent mean \pm S.E.M.

significantly increased $(p<0.01)$ in microglia in the TBI cortex as compared to sham-injured cortex (Fig. 2c).

\section{TBI-induced circulating microparticles activate microglia in vitro}

To examine if circulating MP released after TBI could promote inflammation, we co-cultured BV2 microglia in the presence or absence of enriched MP from the blood of sham-injured and TBI mice (Fig. 3). Equal number of circulating enriched MP from sham and TBI blood (total $8 \times 10^{5}$ ) were incubated with naive BV2 microglia for $24 \mathrm{~h}$, and subsequent activation was assessed by mRNA expression of selected microglial activation markers. When compared to BV2 microglia treated with sham circulating enriched MP, there was a significant increase in $\operatorname{IL}-1 \beta(p<0.01)$ and CCL2 $(p<0.05)$ in recipient microglia co-cultured with TBI circulating enriched MP (Fig. 3) and a trend towards increased in IL-6 and NOS2 expression in this group. There was also a significant increase in P2X7 $(p<0.05)$ in recipient microglia treated with TBI circulating enriched MP when compared to naïve microglia. There was no difference in expression of other pro-inflammatory molecules such as TNF- $\alpha$ and miR-155. 

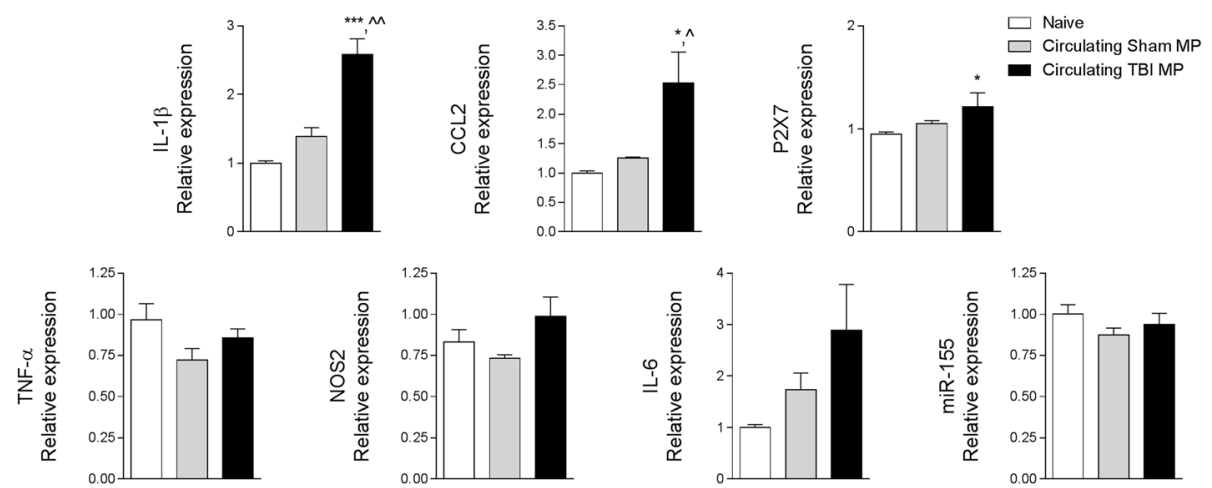

Fig. 3 Circulating blood MP released after TBI activate naive BV2 microglia. Enriched MP were isolated from the blood of sham-injured and TBI mice and were co-cultured with naïve BV2 microglia cells for $24 \mathrm{~h}$. Microglial receptors (P2X7) and pro-inflammatory mediators (IL-1 $\beta$ and CCL2) were significantly increased in BV2 microglia treated with circulating TBI MP $\left({ }^{*} p<0.05\right.$ and ${ }^{* *} p<0.001$ vs naïv; $\wedge p<0.05$ and $\wedge \wedge p<0.01$ vs sham MP; one-way ANOVA with Student-Newman-Keuls correction for multiple comparisons; $n=6 /$ group). There were no significant differences in TNF-a, NOS2, IL-6, and miR-155 expression between treatment groups. Bars represent mean \pm S.E.M.

\section{LPS stimulation increases microparticle release in BV2 microglia, and pro-inflammatory molecules are enriched in microparticles}

We performed a MP release assay in BV2 microglia following LPS stimulation $(20 \mathrm{ng} / \mathrm{ml})$ for $24 \mathrm{~h}$. MP release was quantified by flow cytometry using Calcein AMstained BV2 microglia that were co-stained with the MP marker annexin V. When compared to MP levels in control BV2 microglia, LPS stimulation significantly increased the number of annexin V/calcein AM-positive MP ( $p<0.001$ vs control; Fig. 4a). We next measured IL$1 \beta$ and miR-155 in BV2 microglial cells and isolated enriched MP from the conditioned media to determine the relative expression of pro-inflammatory mediators in MP vs cellular compartments. Following LPS stimulation, IL-1 $\beta$ protein was not detected in the cells, but it was significantly increased in LPS-stimulated enriched MP $(p<0.001$ vs LPS-stimulated cells; Fig. 4b). In addition, following LPS stimulation, miR-155 was significantly increased in BV2 microglial cells ( $p<0.05$ vs control cells; Fig. 4c). Notably, miR-155 was even more highly enriched in LPS-stimulated MP ( $p<0.01$ vs LPSstimulated cells), indicating that enriched MP contain elevated concentrations of pro-inflammatory molecules IL-1 $\beta$ and miR-155 following activation.

\section{LPS-stimulated microparticles activate microglia in vitro}

To test the hypothesis that enriched MP from activated microglia can seed neuroinflammation, we isolated MP from control and LPS-stimulated BV2 microglia and cocultured them with naïve BV2 or primary microglia for $24 \mathrm{~h}$ prior to assessing cellular markers of activation by qPCR. When compared to control enriched-MP-treated recipient $\mathrm{BV} 2$ microglia, there was a significant increase in IL-1 $\beta(p<0.001)$, TNF- $\alpha(p<0.001)$, CCL2 $(p<0.001)$, IL-6 $(p<0.01)$, and NOS2 $(p<0.001)$ mRNA in recipient
BV2 microglia treated with LPS enriched MP (Fig. 5a). There was also a significant increase in miR-155 expression in BV2 microglia $(p<0.001)$ treated with LPS enriched MP when compared to cells treated with control MP (Fig. 5a).

To demonstrate the specific activity of microglialderived enriched MP in activating microglia in these experiments, we neutralized MP by co-incubating them with polyethylene glycol telomere B (PEG-TB), a surfactant that depletes MP without activating blood immune cells [25]. To establish the dose of PEG-TB required to neutralize microglial-derived MP, we performed a dose response study in control and LPS-stimulated enriched MP derived from BV2 microglia and incubated them with increasing concentrations of PEG-TB for $1 \mathrm{~h}$ prior to MP characterization by flow cytometry. We determined that $6 \mu \mathrm{l}$ PEG-TB/100 $\mu \mathrm{l}$ significantly depleted MP levels under both conditions (Fig. 5b), and this concentration was employed to neutralize microglial-derived MP activity in in vitro studies. Next, we determined that when LPS enriched MP were neutralized by PEG-TB and co-cultured with naïve BV2 microglia for $24 \mathrm{~h}$, markers of microglial activation were significantly reduced. Specifically, recipient BV2 microglia incubated with LPS MP + PEG-TB had significantly reduced expression of IL-1 $\beta \quad(p<0.001)$ and TNF- $\alpha \quad(p<0.001)$ when compared to the LPS MP group (Fig. $5 \mathrm{c}$ ). We confirmed the effects of LPS-stimulated enriched MP on primary cortical microglia. There was a significant increase in IL-1 $\beta(p<0.01)$, TNF- $\alpha(p<0.01)$, and IL-6 ( $p$ $<0.05)$ mRNA in recipient primary microglia treated with LPS enriched MP when compared to control MPtreated cells (Fig. 6). There was also a significant increase in miR-155 expression in primary microglia $(p<0.01)$ treated with LPS enriched MP when compared to cells treated with control MP (Fig. 6). 

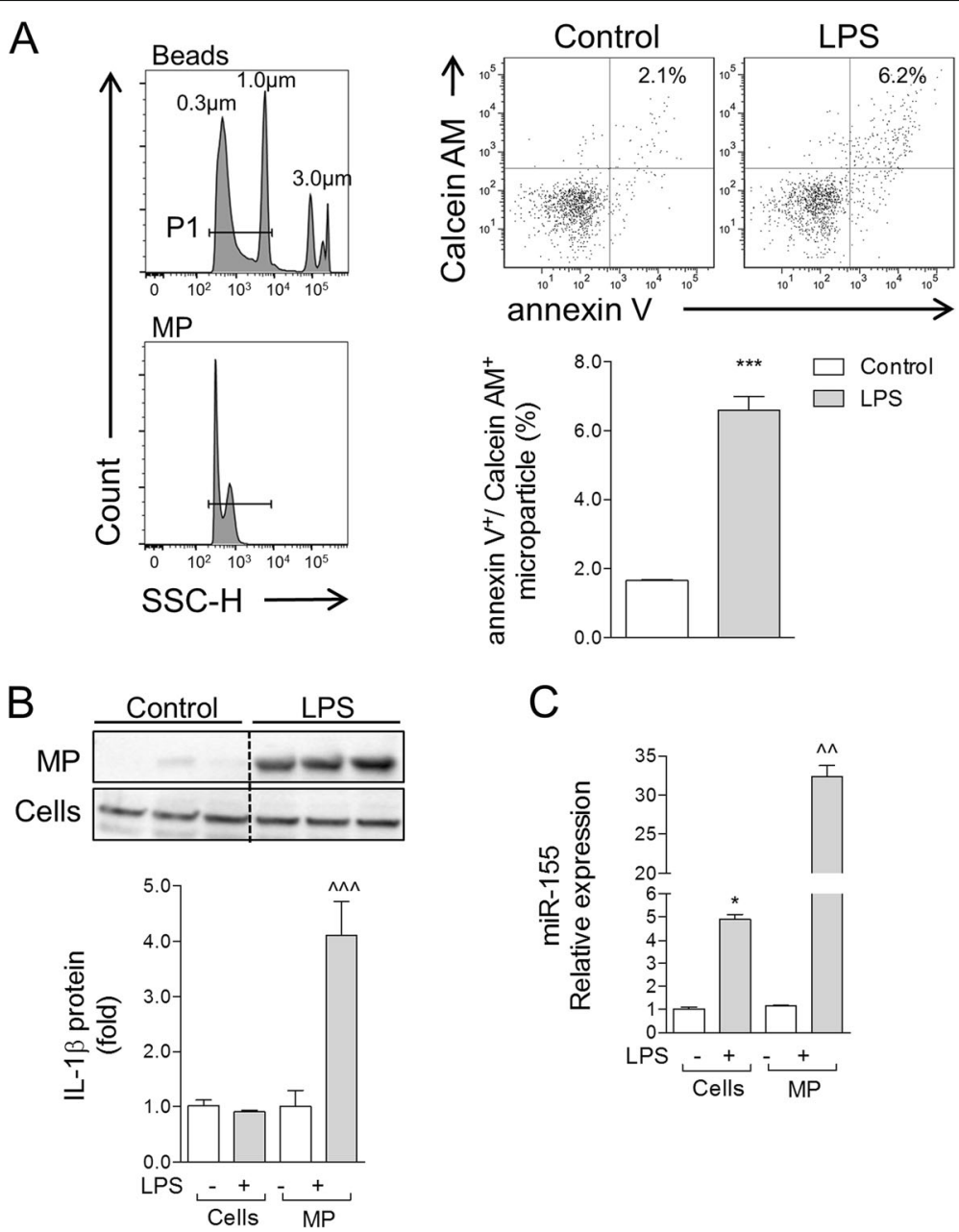

Fig. 4 Pro-inflammatory mediators are enriched in MP following lipopolysaccharide stimulation of BV2 microglia. a Calcein AM-stained BV2 microglia were stimulated with LPS $(20 \mathrm{ng} / \mathrm{ml})$ for $24 \mathrm{~h}$, and MP were isolated by differential centrifugation and stained with anti-annexin V, prior to characterization by flow cytometry. When compared to MP levels in control BV2 microglia, LPS stimulation significantly increased the number of annexin V/calcein AM-positive MP ( ${ }^{* * *} p<0.001$ vs control; Student's $t$ test; $n=4 /$ group). $\mathbf{b}$ IL-1 $\beta$ protein expression in enriched MP vs cell lysates of control and LPS-stimulated BV2 microglia. Western blot analysis demonstrated that IL-1 $\beta$ protein was significantly increased in enriched MP following LPS stimulation $(\wedge \wedge \wedge p<0.001$ vs control MP; one-way ANOVA with Student-Newman-Keuls correction for multiple comparisons; $n=3$ /group). Lanes 1, 2, and 3 in both control and LPS refer to sample replicates. c miR-155 expression in enriched MP vs cell lysates of control and LPS-stimulated BV2 microglia. miR-155 was significantly increased in cell lysates of BV2 microglia following LPS stimulation ( ${ }^{*} p<0.05$ vs control cells), and its expression was elevated further in enriched MP ( $\wedge \wedge p<0.01$ vs control MP; one-way ANOVA with Student-Newman-Keuls correction for multiple comparisons; $n=4 /$ group). Bars represent mean \pm S.E.M. Data represent results of three independent experiments

Finally, we confirmed that the effects of LPS enriched MP on microglial activation were not due to LPS crossover. We measured LPS levels in the LPS enriched MP samples using a limulus amebocyte lysate (LAL) assay and determined that the LPS concentration was negligible $(0.081 \pm 0.009 \mathrm{EU} / \mathrm{ml}(<0.1 \mathrm{ng}))$ and well below LPS concentrations previously shown to transfer LPS activity in enriched MP [34].

\section{Microglial-derived microparticles can seed brain inflammation in vivo}

To determine whether microglial-derived enriched MP could seed neuroinflammation in the uninjured brain, we isolated enriched MP from control and LPSstimulated BV2 microglia and stereotactically injected them into the cortex of adult male C57BL/6 mice. As a control to demonstrate the specific activity of microglialderived enriched MP in promoting brain inflammation, we neutralized enriched MP by co-incubating them with PEG-TB as described before. After $24 \mathrm{~h}$, cortical tissue was collected and markers of brain inflammation were assessed. When LPS enriched MP were injected into the uninjured cortex, they produced a robust neuroinflammatory response resulting in a significant increase in IL$1 \beta(p<0.01)$, NOS2 $(p<0.01)$, TNF- $\alpha(p<0.001)$, IL-6 $(p<0.05)$, and miR-155 $(p<0.01)$ when compared to the 


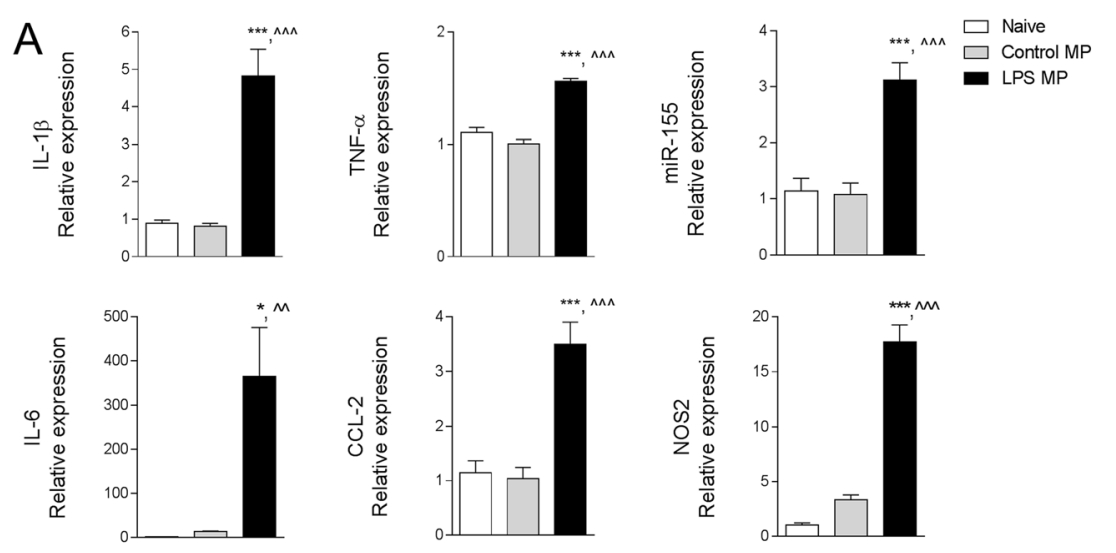

B

C

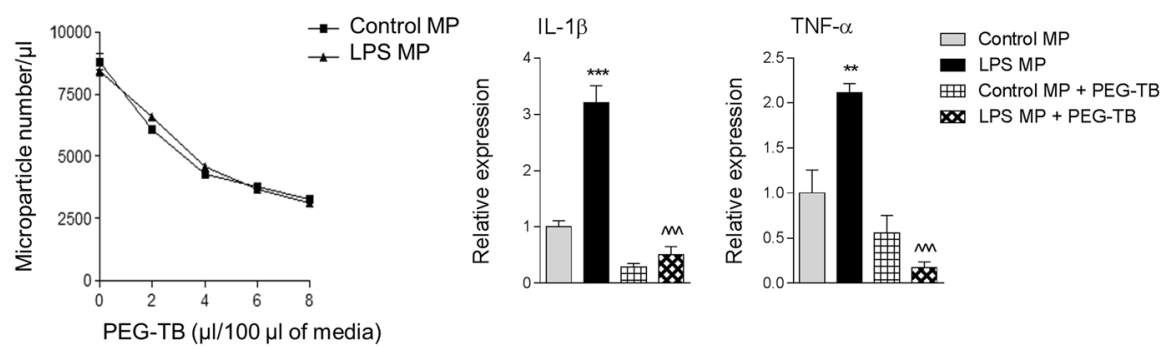

Fig. 5 Lipopolysaccharide-stimulated MP activate BV2 microglia. a Enriched MP were isolated from control and LPS-stimulated BV2 microglia and were co-cultured with naïve BV2 microglia for 24 h. Pro-inflammatory mediators (IL-1 $\beta$, TNF-a, miR-155, IL-6, CCL2, and NOS2) were significantly increased in BV2 microglia treated with LPS MP $\left({ }^{*} p<0.05\right.$ and ${ }^{* * *} p<0.001$ vs naïve; $\wedge \wedge p<0.01$ and $\wedge \wedge \wedge p<0.001$ vs control MP; one-way ANOVA with Student-Newman-Keuls correction for multiple comparisons; $n=4 /$ group). Data represent results of three independent experiments. $\mathbf{b}$ MP neutralization using PEG-TB. Enriched MP from control and LPS-stimulated BV2 microglia were incubated with increasing concentrations of PEG-TB for $1 \mathrm{~h}$, and number of MP were quantified by flow cytometry. $6 \mu \mathrm{l} \mathrm{PEG-TB/100} \mathrm{\mu l} \mathrm{resulted} \mathrm{in} \mathrm{significant} \mathrm{depletion} \mathrm{of} \mathrm{MP} \mathrm{under} \mathrm{both} \mathrm{conditions.} \mathrm{c} \mathrm{Naive} \mathrm{BV2}$ microglia were co-cultured with control or LPS-stimulated MP \pm PEG-TB $(6 \mu / / 100 \mu l)$ for $24 \mathrm{~h}$. LPS MP treatment increased IL-1 $\beta$ and TNF- $\mathrm{a}$ in BV2 microglia $\left({ }^{* *} p<0.01\right.$ and ${ }^{* * *} p<0.001$ vs control MP), whereas co-treatment with PEG-TBI resulted in a significant decrease in IL-1 $\beta$ and TNF-a expression $(\wedge \wedge \wedge p<0.001$ vs LPS MP; one-way ANOVA with Student-Newman-Keuls correction for multiple comparisons; $n=6 /$ group). Bars represent mean \pm S.E.M.
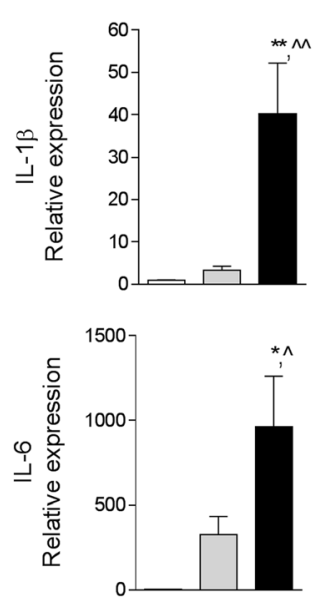

Fig. 6 Lipopolysaccharide-stimulated MP activate primary cortical microglia. Enriched MP were isolated from control and LPS-stimulated BV2 microglia and were co-cultured with primary cortical microglia for $24 \mathrm{~h}$. Pro-inflammatory mediators (IL-1 $\beta$, TNF-a, miR-155, IL-6, CCL2, and NOS2) were significantly increased in primary microglia treated with LPS MP $\left({ }^{*} p<0.05,{ }^{* *} p<0.001\right.$, and ${ }^{* * *} p<0.001$ vs naïve; $\wedge p<0.05$ and $\wedge \wedge p<0.01$ vs control MP; one-way ANOVA with Student-Newman-Keuls correction for multiple comparisons; $n=5 /$ group). Bars represent mean \pm S.E.M. 
control MP-injected group (Fig. 7). Notably, when LPS enriched MP were neutralized by PEG-TB and injected into the uninjured cortex, the cortical neuroinflammatory response was attenuated, such that the LPS enriched MP + PEG-TB group had significantly reduced expression of IL-1 $\beta \quad(p<0.001)$, NOS2 $(p<$ $0.001)$, TNF- $\alpha(p<0.001)$, IL-6 $(p<0.05)$, and miR-155 $(p<0.01)$ when compared to the LPS enriched MP group (Fig. 7). Intracortical injection with control MP, control MP + PEG-TB, or PEG-TB alone did not promote a neuroinflammatory response in the cortex.

In a separate study, control and LPS enriched MP were stereotactically injected into the cortex of uninjured C57BL/6 mice. At 7 days post-surgery, mice were euthanized and brain tissue was saline perfused and fixed for immunohistochemical analysis of microglial activation in the cortex, hippocampus, and thalamus using Iba-1 and P2Y12 immunostaining. There was a significant increase in Iba-1 staining in the ipsilateral cortex, hippocampus, and thalamus of C57BL/6 injected with LPS enriched MP $(p<0.001)$ when compared to mice injected with control MP or sham mice (Fig. 8a-c). Further morphological analysis of P2Y12-positive microglia using Neurolucida reconstruction software revealed that C57BL/6 mice injected with LPS enriched MP resulted in increased microglial activation. Specifically, microglial ramifications were significantly reduced in length in the cortex and hippocampus of the LPS enriched-MPinjected cortex $(p<0.01$ for both vs control MP), and the microglial cell body area was significantly increased in the cortex $(p<0.001)$, hippocampus $(p<0.01)$, and thalamus ( $p<0.01$ vs control MP; Fig. 9a-c). These data indicate that enriched MP derived from LPS-stimulated microglia produce a robust neuroinflammatory response when injected into the cortex of uninjured mice.

\section{Microparticles produced by microglia/macrophage isolated from the TBI brain induce neuroinflammation in non-injured mice}

To relate MP-mediated seeding of neuroinflammation to secondary injury mechanisms in the TBI brain, we subjected adult male C57BL/6 mice to sham or moderatelevel TBI and isolated microglia/macrophages from the ipsilateral cortex at 7 days post-injury using MACS CD11b magnetic beads. We then cultured CD11b-positive cells for $24 \mathrm{~h}$ and collected microglia/macrophage-derived enriched MP from sham and TBI samples. Equal numbers of enriched MP (total $8 \times 10^{3} \mathrm{MP}$ ) were stereotactically injected into the cortex of uninjured adult male C57BL/6 mice, and cortical tissue was collected $24 \mathrm{~h}$ later to assess markers of neuroinflammation. Injection of sham MP significantly increased IL-1 $\beta$ $(p<0.001)$ and TNF- $\alpha(p<0.001)$ expression, but not miR-155 expression, when compared to the naïve control group (Fig. 10). Furthermore, injection of TBI enriched MP significantly increased IL-1 $\beta(p<0.001)$, TNF- $\alpha(p<0.05)$, and miR-155 $(p<0.01)$ expression in the cortex when compared to the sham MP-injected group. Although there was a modest increase in IL-6 and NOS2 expression in sham MP and TBI enriched MP-injected groups when compared to the naive control group, these changes did not reach statistical significance. These data indicate that enriched MP derived from the microglia/macrophages
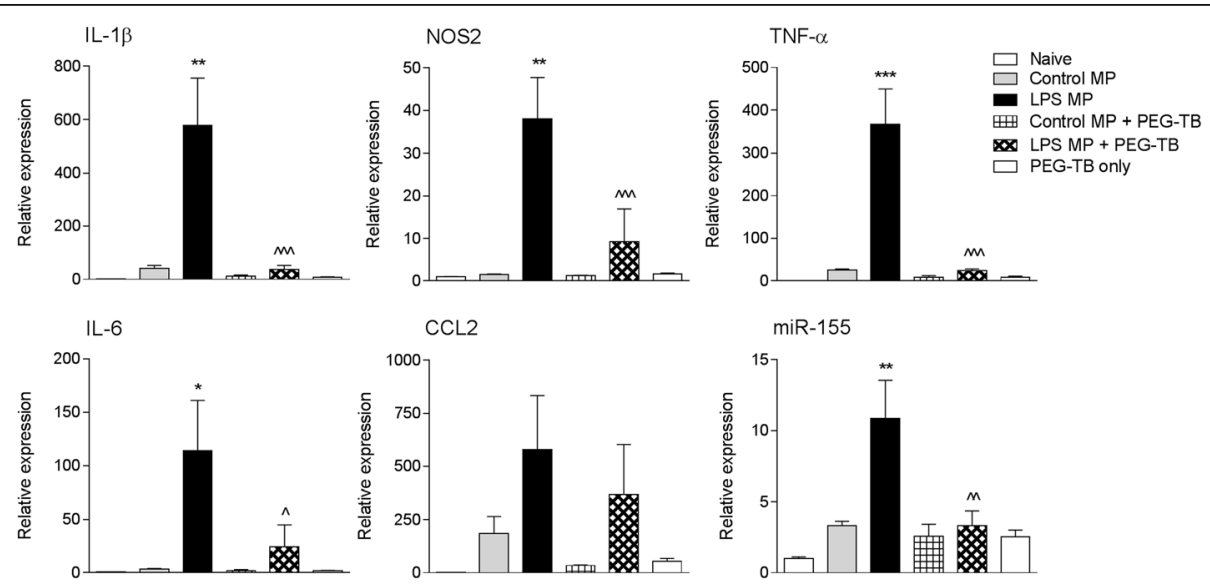

Fig. 7 Lipopolysaccharide-stimulated MP increase neuroinflammation in the cortex of uninjured mice. Enriched MP were isolated from control and LPS-stimulated BV2 microglia and were treated \pm PEG-TB $(6 \mu \mathrm{l} / 100 \mu \mathrm{l})$ prior to being stereotactically injected into the cortex of adult male C57BL/6 mice. Markers of cortical neuroinflammation were measured at $24 \mathrm{~h}$ postinjection. There was a significant increase in pro-inflammatory mediators (IL-1 $\beta$, TNF- $a$, miR-155, IL-6, and NOS2) in the cortex of LPS MP-injected mice (** $p<0.01,{ }^{* * *} p<0.001$ vs control MP-injected group). Neutralization of LPS MP prior to injection resulted in a significant decrease in each pro-inflammatory mediator $(\wedge p<0.05, \wedge \wedge p<0.01$, $\wedge \wedge \wedge p<0.001$ vs LPS MP-injected group; one-way ANOVA with Student-Newman-Keuls correction for multiple comparisons; $n=6 / \mathrm{group}$ ). Bars represent mean \pm S.E.M. 


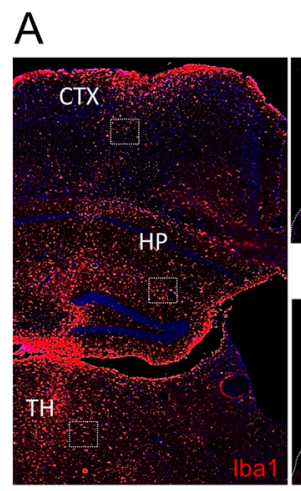

LPS MP
$\mathrm{B}$

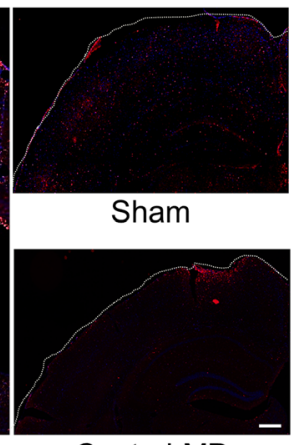

Control MP
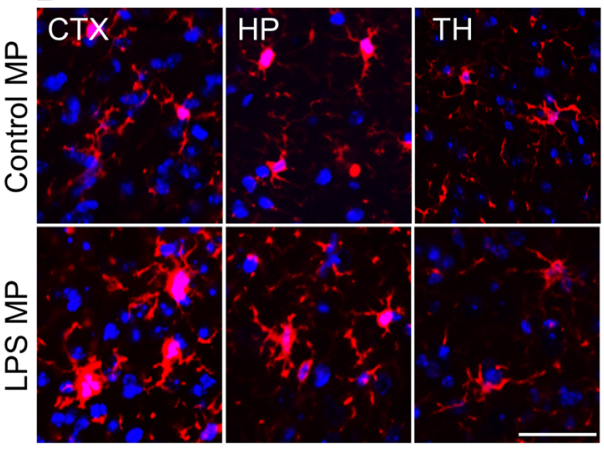

C

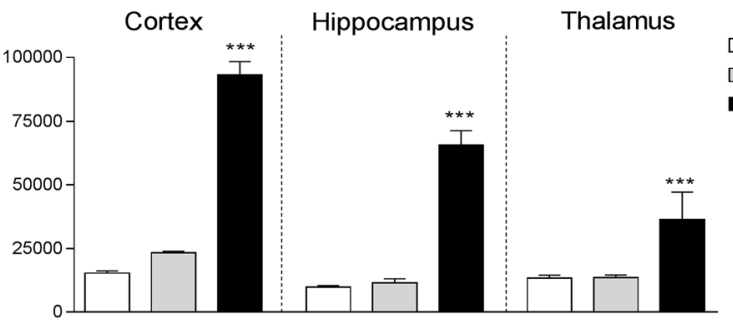

Fig. 8 Lipopolysaccharide-stimulated MP increase microglial activation in the cortex of uninjured mice. Enriched MP were isolated from control and LPS-stimulated BV2 microglia and were stereotactically injected into the cortex of adult male C57BL/6 mice. Iba- 1 immunocytochemistry was performed at 7 days postinjection. a Representative Iba-1 staining (red) in the cortex (CTX), hippocampus (HP), and thalamus (TH). Images taken at -2.06 mm from the bregma; scale bar $=50 \mu \mathrm{m}$. b High-magnification images in control MP- and LPS MP-injected mice in the CTX, HP, and TH. LPS MP-injected Iba-1-positive microglia had enlarged cell body and thicker projection indicative of increased activation status. Scale bar $=100 \mu \mathrm{m}$. c Quantification of Iba-1 staining in the cortex, hippocampus, and thalamus at 7 days postinjection. There was a significant increase in Iba-1 immunoreactivity in the LPS MP-injected group when compared to the control MP-treated group ${ }^{* * *} p<0.001$ vs control MP; one-way ANOVA with Student-Newman-Keuls correction for multiple comparisons; $n=4$ /group). Bars represent mean \pm S.E.M.

isolated from the TBI brain produce a robust neuroinflammatory response when injected into the uninjured cortex.

\section{Discussion}

TBI initiates complex local and systemic immune responses. However, the precise nature of posttraumatic neuroinflammation, its regulatory mechanisms, and role in secondary injury remain to be elucidated [35]. Recent studies have offered intriguing evidence regarding the potential role played by extracellular vesicles in cell-cell communication between immune cells and their targets [36, 37]. In the present study, we examined the release of microparticles (MP), a special class of extracellular vesicles, from the injured brain and their contribution to mechanisms of microglial activation and related neuroinflammation.

Although high levels of MP have been detected in the blood of TBI patients [18, 19], their cellular origins are not well defined. Clinical studies indicate that MP in the blood are primarily derived from platelets, with much smaller fractions released from erythrocytes, granulocytes, monocytes, lymphocytes, and endothelial cells [18, 19, 21, 38, 39]. Recent studies have highlighted the potential systemic pathological effects of MP following brain injury, including brain-trauma-associated coagulopathy [21]. MP released from neurons (NSE-positive MP) and astrocytes (GFAPpositive MP) accumulated in the circulation within $3 \mathrm{~h}$ of experimental TBI and were associated with microvascular fibrin deposition in the heart, kidney, and lung [21]. We observed a significant increase in total circulating MP at $24 \mathrm{~h}$ post-injury. Furthermore, an evaluation of the origin of circulating MP based on the presence of unique markers derived from parental cells revealed that microglial MP displayed the greatest increase (approximately twofold) following TBI, accounting for nearly $15 \%$ of total circulating MP. Although P2Y12 is also expressed on platelets [40], the detected P2Y12-positive MP were co-stained with CD45, a unique myeloid cell marker that is not expressed on platelets [41, 42], indicating that the P2Y12positive MP enriched in the circulation following TBI were not derived from platelets. These data indicate that microglial-derived MP are released by the TBI brain and reach the systemic circulation. Importantly, we observed robust neuroinflammatory responses in the injured brain-with activation of P2Y12-positive microglia in the cortex, hippocampus, and thalamus-associated with upregulated expression of classical pro-inflammatory mediators (IL-1 $\beta$, TNF- $\alpha$, CCL2, IL-6, NOS2, and miR-155) in the injured cortex. 

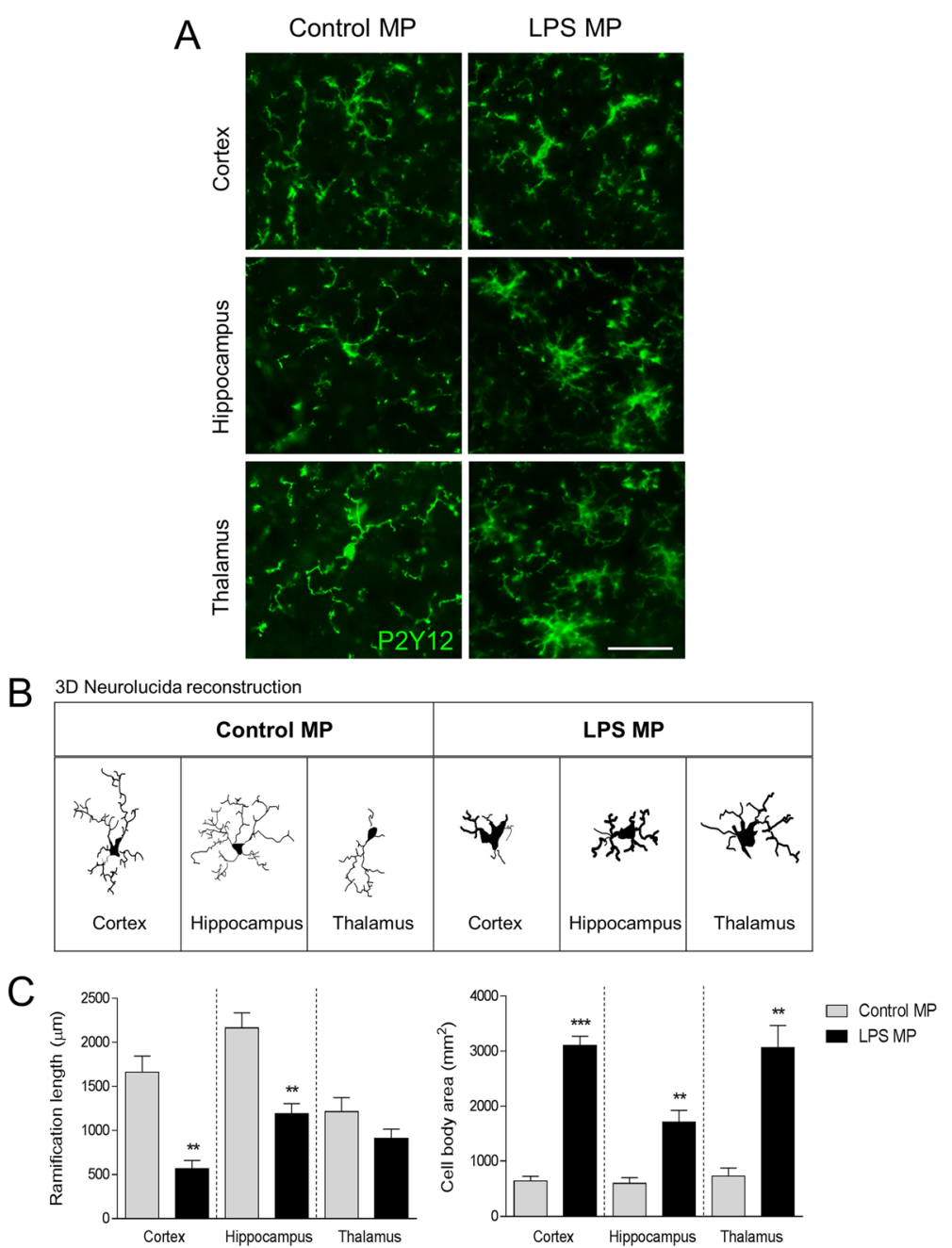

Fig. 9 Lipopolysaccharide-stimulated MP alter P2Y12 microglial morphology of the cortex of uninjured mice. Enriched MP were isolated from control and LPS-stimulated BV2 microglia and were stereotactically injected into the cortex of adult male C57BL/6 mice. P2Y12 immunocytochemistry was performed at 7 days postinjection. a High-magnification images of P2Y12-positive microglia (green) in control MP- and LPS MP-injected mice in the cortex (CTX), hippocampus (HP), and thalamus (TH). LPS MP-injected P2Y12-positive microglia have enlarged cell body and thicker projection indicative of increased activation status. Scale bar $=100 \mu \mathrm{m}$. b P2Y12-positive microglia in the CTX, HP, and TH of control MP- and LPS MP-injected mice. c Morphological analysis of P2Y12-positive microglia using 3D-reconstruction Neurolucida software. When compared to the control MP-injected group, P2Y12-positive microglia in the LPS MP-injected group had reduced ramification length in the cortex and hippocampus (** $p<0.01$; Student's $t$ test), but not in the thalamus. In addition, the LPS MP-injected group had enlarged cell body area in each region $\left(*^{* *} p<0.01\right.$ and ${ }^{* * *} p<0.001$ vs control MP; Student's $t$ test; $n=4 /$ group). Bars represent mean \pm S.E.M.

Previous studies indicated that microglia and other myeloid cells in vitro can shed MP, which store and release pro-inflammatory molecules such as IL-1 $\beta$ [43], inflammasome components, and MHCII protein [44]. These data suggest that MP produced by reactive myeloid cells, such as microglia, may propagate inflammation and the rapid dissemination and presentation of antigens. A major finding of our study was that circulating enriched MP from TBI mice significantly activated recipient microglia in vitro and up-regulated pro-inflammatory signaling molecules such as IL-1 $\beta$ and CCL2.

Similarly, MP from LPS-stimulated BV2 microglia significantly increased IL-1 $\beta$, TNF- $\alpha$, CCL2, IL-6, NOS2, and miR-155 expression in recipient BV2 or primary microglia, confirming the ability of MP to act as independent microglial activators. LPS stimulation of microglia is an established in vitro model for TBI neuroinflammation because LPS up-regulates key pro-inflammatory mediators in microglia (IL-1 $\beta$, TNF- $\alpha$, NOS2, CCL2) that are robustly up-regulated in microglia/macrophages in the injured cortex and hippocampus following TBI [31, 45, 46]. In the current study, we demonstrated that LPS-stimulated microglia release MP into conditioned media that can induce pro-inflammatory responses in non-activated recipient microglial cells. Importantly, MP depleted of their content by addition of 


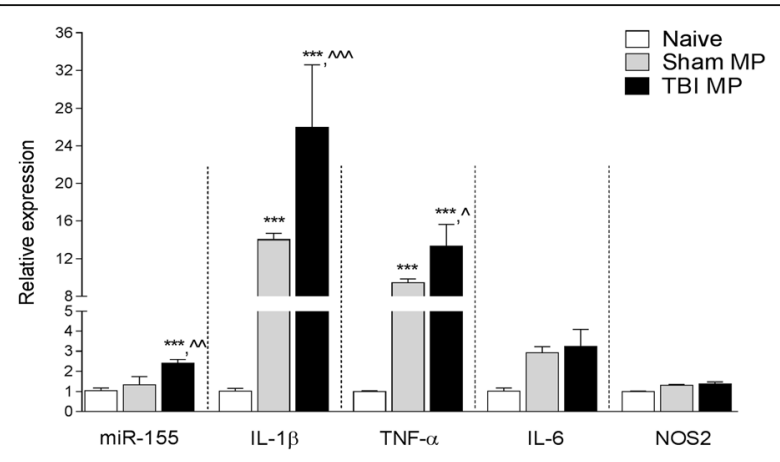

Fig. 10 MP isolated from CD11b-isolated microglia/macrophages following TBI increase neuroinflammation in the cortex of uninjured mice. CD11b-microglia/macrophages in the cortex of sham and TBI were isolated at 7 days post-injury and cultured for $24 \mathrm{~h}$ prior to collecting MP. Enriched MP were stereotactically injected into the cortex of adult male C57BL/6 mice and markers of cortical neuroinflammation were measured at $24 \mathrm{~h}$ postinjection. There was a significant increase in pro-inflammatory mediators ( $\mathrm{L}-1 \beta$ and TNF-a) in the cortex of the control MP-injected group ${ }^{* * *} p<0.001$ vs naïve group). When compared to the control MP-injected group, there was a further significant increase in pro-inflammatory mediators ( $\mathrm{LL}-1 \beta$, TNF-a, and miR-155) in the cortex of the TBI MP-injected group $(\wedge p<0.05, \wedge \wedge p<0.01, \wedge \wedge \wedge p<0.001$ vs control MP-injected group; one-way ANOVA with Student-Newman-Keuls correction for multiple comparisons; $n=5$ /group). Bars represent mean \pm S.E.M.

MP-neutralizing surfactant, PEG-TB, lost their ability to activate recipient cells, thus demonstrating the critical function of MP in promoting the pro-inflammatory response in the target cells.

We demonstrated that IL-1 $\beta$ and miR-155 were highly enriched in MP that can propagate a pro-inflammatory response in recipient cells. IL- $1 \beta$ does not contain an Nterminal signal sequence for secretion and therefore must be released from the cell through alternative mechanisms [47]. LPS stimulation increased IL-1 $\beta$ protein in enriched MP but not in microglia cells, where only IL$1 \beta$ mRNA was elevated. Astrocyte-derived ATP has been shown to induce extracellular vesicle shedding and IL$1 \beta$ release in microglia through a P2X7 receptordependent mechanism [43]. Notably, ATP is released following acute brain injury and promotes a powerful chemotactic response in microglia towards the site of injury [15]. In our study, the P2X7 receptor was significantly increased at sites of inflammation in the injured cortex; thus, P2X7 receptor-dependent mechanisms of MP release in microglia may be involved in the propagation of inflammation following TBI. Other mechanisms of MP release in microglia-such as MP fusion with the cell membrane, macropinocytosis [48], and direct release of their contents into the cytosol [37], as well as indirect mechanisms through binding of pattern-recognition receptors in the endosomal compartment (primarily Tolllike receptor 7/8-TLR7/8) [49] - may also contribute to the propagating neuroinflammation and warrant further investigation.

MP can also transfer miRs [50-53]. The levels of miR155, a well-characterized pro-inflammatory miR in microglia [54], were highly enriched in microglialderived MP. miR-155 has been shown to be a key regulator of the inflammatory response in experimental models of stroke, Parkinson's disease, amyotrophic lateral sclerosis, and multiple sclerosis [55-58]. We also demonstrated that miR-155 was significantly increased in the cortex of TBI mice, and its expression was significantly increased when LPS-stimulated MP from BV2 microglia or MP from CD11b-positive microglia/macrophages from the TBI brain were injected into the cortex of uninjured mice. Secreted miR-155 from adipocyte-derived MP in obese mice induces a pro-inflammatory activation state in macrophages that causes chronic inflammation and local insulin resistance [59]. Thus, secreted miR-155 from MP may be an important driver of neuroinflammation following TBI.

The pathogenic role of MP in the inflammatory response was demonstrated in vivo by showing that injection of microglial-derived MP induces neuroinflammation at the site of injection and at more distant sites. Cortical injection of enriched MP isolated from LPS-stimulated BV2 microglia significantly increased markers of microglial activation (Iba-1 and P2Y12 morphological transformation) in the ipsilateral cortex, hippocampus, and thalamus and upregulated pro-inflammatory markers in the cortex. These data support prior research that demonstrated that myeloid-derived microvesicles that are detected in the CSF of multiple-sclerosis patients and closely associate with disease course can propagate inflammation in vivo when injected locally [60]. Furthermore, cortical injections of enriched MP collected from ex vivo cultures of microglia/ macrophages purified from TBI brain markedly induce expression of pro-inflammatory molecules miR-155, IL-1 $\beta$, and TNF- $\alpha$ in the cortex of non-injured animals. To our knowledge, these latter observations describe the first use of purified brain microglia to demonstrate the transfer of the posttraumatic neuroinflammatory phenotype using MP as a vehicle.

It is important to recognize that the enriched MP population obtained using our experimental protocol may also contain other types of extracellular vesicles such as exosomes. In this study, we used established flow cytometry protocols to characterize MP properties [25], but this technique is limited to the identification of particles greater than $300 \mathrm{~nm}$, preventing the detection of smaller microvesicles and all exosomes [61]. Electron microscopy can directly show that extracellular vesicles exist in a sample, but fixation processes involved in the technique can alter vesicle shape and size [62]. Other 
techniques such as dynamic light scattering and nanoparticle-tracking analyses have several limitations and introduce biases when characterizing extracellular vesicle properties $[61,63,64]$. The focus of the current study was the pathophysiological responses of microglial-derived MP rather than the nature of the enriched microvesicles. We determined that enriched MP derived from microglia could propagate neuroinflammation in vivo. We selectively depleted enriched MP by incubating them with PEG-TB, a drug that emulsifies MP without modifying circulating leukocyte activation $[2,25]$. When we co-cultured depleted MP from LPS-stimulated BV2 microglia with recipient naïve BV2 microglia, or injected depleted MP into the cortex of uninjured mice, pro-inflammatory responses were significantly attenuated. These results support our hypothesis that it is the enriched MP component of purified extracellular vesicles derived from microglia that propagates neuroinflammation.

\section{Conclusions}

The major findings of these studies are that (1) microglialderived MP are released after TBI, (2) circulating enriched MP from the TBI animals can activate microglia in vitro, (3) LPS activation increases MP release from microglia and elevates their content of pro-inflammatory mediators IL-1 $\beta$ and miR-155, and (4) enriched MP from activated microglia in vitro or CD11b-isolated microglia from the TBI brain ex vivo are sufficient to initiate neuroinflammation following intracortical injection in naïve animals. Given their ability to independently initiate pro-inflammatory responses, MP derived from activated microglia may provide a novel therapeutic target for TBI and other neurodegenerative disorders associated with neuroinflammation.

\section{Abbreviations \\ CCl: Controlled cortical impact; CCL2: C-C motif chemokine ligand 2; IL- 1ß: Interleukin-1 $\beta$; IL-6: Interleukin-6; miR-155: MicroRNA-155; MP: Microparticles; NOS2: Nitric oxide synthase 2; P2X7: P2X purinoceptor 7 PEG-TB: Polyethylene glycol telomere B; PS: Phosphatidylserine; SOD1: Superoxide dismutase 1; TBI: Traumatic brain injury; TNF-a: Tumor necrosis factor-alpha}

\section{Acknowledgements}

We thank Dr. Boris Sabirzhanov and Dr. Junfang Wu for advice and expert technical support.

The views expressed in this article are those of the authors and do not necessarily reflect the official policy or position of the Air Force, the Department of Defense, or the US Government.

\section{Funding}

This study was supported by NIH grants R01NS037313 (A.I. Faden), R01 NS052568 (A.I. Faden), and R01NS082308 (D.J. Loane). This study was also supported by the 711 HPW/XPT under Cooperative Agreement number FA8650-15-2-6606. The funder had no role in the study design, data collection, and analysis, decision to publish, or preparation of the manuscript.

\section{Availability of data and materials}

All the datasets and materials supporting the conclusions of this article are presented in the manuscript.

\section{Authors' contributions}

AK, BAS, DJL, SRT, and AIF designed research; AK, YM, GA, NK, and AK performed the research; AK and YM analyzed the data; AK, BAS, DJL, and AIF wrote the paper. All authors read and approved the final manuscript.

\section{Competing interests}

The authors declare that they have no competing interests.

\section{Consent for publication}

Consent for publication is not applicable for this manuscript.

\section{Ethics approval}

All animal experiment and surgical procedures were carried out in accordance with animal use protocols approved by the Institutional Animal Care and Use Committee (IACUC) at the University of Maryland School of Medicine.

\section{Author details}

'Department of Anesthesiology, University of Maryland School of Medicine, Baltimore, MD, USA. ${ }^{2}$ Shock, Trauma and Anesthesiology Research (STAR) Center, University of Maryland School of Medicine, Health Sciences Facility II (HSFII), \#S247 20 Penn Street, Baltimore, MD 21201, USA. ${ }^{3}$ Department of Emergency Medicine, University of Maryland School of Medicine, Baltimore, MD, USA.

Received: 30 December 2016 Accepted: 18 February 2017

Published online: 15 March 2017

\section{References}

1. Burnier L, Fontana P, Kwak BR, Angelillo-Scherrer A. Cell-derived microparticles in haemostasis and vascular medicine. Thromb Haemost. 2009;101:439-51.

2. Bohman LE, Riley J, Milovanova TN, Sanborn MR, Thom SR, Armstead WM. Microparticles impair hypotensive cerebrovasodilation and cause hippocampal neuronal cell injury after traumatic brain injury. J Neurotrauma. 2016:33:168-74.

3. Davizon P, Munday AD, Lopez JA. Tissue factor, lipid rafts, and microparticles. Semin Thromb Hemost. 2010;36:857-64.

4. Zappulli V, Friis KP, Fitzpatrick Z, Maguire CA, Breakefield XO. Extracellular vesicles and intercellular communication within the nervous system. J Clin Invest. 2016;126:1198-207.

5. Castro-Seoane R, Hummerich H, Sweeting T, Tattum MH, Linehan JM, Fernandez de Marco M, Brandner S, Collinge J, Klohn PC. Plasmacytoid dendritic cells sequester high prion titres at early stages of prion infection. PLoS Pathog. 2012;8:e1002538.

6. Klohn PC, Castro-Seoane R, Collinge J. Exosome release from infected dendritic cells: a clue for a fast spread of prions in the periphery? I Infect. 2013;67:359-68.

7. Grad LI, Fernando SM, Cashman NR. From molecule to molecule and cell to cell: prion-like mechanisms in amyotrophic lateral sclerosis. Neurobiol Dis. 2015;77:257-65.

8. Basso M, Pozzi S, Tortarolo M, Fiordaliso F, Bisighini C, Pasetto L, Spaltro G, Lidonnici D, Gensano F, Battaglia E, et al. Mutant copper-zinc superoxide dismutase (SOD1) induces protein secretion pathway alterations and exosome release in astrocytes: implications for disease spreading and motor neuron pathology in amyotrophic lateral sclerosis. J Biol Chem. 2013;288: 15699-711.

9. Rajendran L, Honsho M, Zahn TR, Keller P, Geiger KD, Verkade P, Simons K Alzheimer's disease beta-amyloid peptides are released in association with exosomes. Proc Natl Acad Sci U S A. 2006;103:11172-7.

10. Dinkins MB, Dasgupta S, Wang G, Zhu G, Bieberich E. Exosome reduction in vivo is associated with lower amyloid plaque load in the 5XFAD mouse model of Alzheimer's disease. Neurobiol Aging. 2014;35:1792-800.

11. Asai H, Ikezu S, Tsunoda S, Medalla M, Luebke J, Haydar T, Wolozin B, Butovsky O, Kugler S, Ikezu T. Depletion of microglia and inhibition of exosome synthesis halt tau propagation. Nat Neurosci. 2015;18:1584-93.

12. Yuyama K, Sun H, Sakai S, Mitsutake S, Okada M, Tahara H, Furukawa J, Fujitani N, Shinohara Y, Igarashi Y. Decreased amyloid-beta pathologies by intracerebral loading of glycosphingolipid-enriched exosomes in Alzheimer model mice. J Biol Chem. 2014;289:24488-98. 
13. An K, Klyubin I, Kim Y, Jung JH, Mably AJ, O'Dowd ST, Lynch T, Kanmert D, Lemere CA, Finan GM, et al. Exosomes neutralize synaptic-plasticitydisrupting activity of $A \beta$ assemblies in vivo. Mol Brain. 2013;6:47.

14. Loane DJ, Faden Al. Neuroprotection for traumatic brain injury: translational challenges and emerging therapeutic strategies. Trends Pharmacol Sci. 2010;31:596-604

15. Davalos D, Grutzendler J, Yang G, Kim JV, Zuo Y, Jung S, Littman DR, Dustin ML, Gan WB. ATP mediates rapid microglial response to local brain injury in vivo. Nat Neurosci. 2005;8:752-8.

16. Kumar A, Loane DJ. Neuroinflammation after traumatic brain injury: opportunities for therapeutic intervention. Brain Behav Immun. 2012;26:1191-201.

17. Loane DJ, Kumar A, Stoica BA, Cabatbat R, Faden Al. Progressive neurodegeneration after experimental brain trauma: association with chronic microglial activation. J Neuropathol Exp Neurol. 2014;73:14-29.

18. Morel N, Morel O, Petit L, Hugel B, Cochard JF, Freyssinet JM, Sztark F, Dabadie P. Generation of procoagulant microparticles in cerebrospinal fluid and peripheral blood after traumatic brain injury. J Trauma. 2008;64:698-704.

19. Nekludov M, Mobarrez F, Gryth D, Bellander BM, Wallen H. Formation of microparticles in the injured brain of patients with severe isolated traumatic brain injury. J Neurotrauma. 2014;31:1927-33.

20. Andrews AM, Lutton EM, Merkel SF, Razmpour R, Ramirez SH. Mechanical injury induces brain endothelial-derived microvesicle release: implications for cerebral vascular injury during traumatic brain injury. Front Cell Neurosci. 2016;10:43.

21. Tian $Y$, Salsbery $B$, Wang $M$, Yuan $H$, Yang J, Zhao Z, Wu X, Zhang $Y$, Konkle BA, Thiagarajan $\mathrm{P}$, et al. Brain-derived microparticles induce systemic coagulation in a murine model of traumatic brain injury. Blood. 2015;125:2151-9.

22. Loane DJ, Pocivavsek A, Moussa CE, Thompson R, Matsuoka Y, Faden Al, Rebeck GW, Burns MP. Amyloid precursor protein secretases as therapeutic targets for traumatic brain injury. Nat Med. 2009;15:377-9.

23. Yang M, Bhopale VM, Thom SR. Separating the roles of nitrogen and oxygen in high pressure-induced blood-borne microparticle elevations, neutrophil activation, and vascular injury in mice. J Appl Physiol (1985). 2015;119:219-22.

24. Thom SR, Yang M, Bhopale VM, Milovanova TN, Bogush M, Buerk DG. Intramicroparticle nitrogen dioxide is a bubble nucleation site leading to decompression-induced neutrophil activation and vascular injury. J Appl Physiol (1985). 2013;114:550-8.

25. Thom SR, Yang M, Bhopale VM, Huang S, Milovanova TN. Microparticles initiate decompression-induced neutrophil activation and subsequent vascular injuries. J Appl Physiol (1985). 2011;110:340-51.

26. Yang M, Kosterin P, Salzberg BM, Milovanova TN, Bhopale VM, Thom SR. Microparticles generated by decompression stress cause central nervous system injury manifested as neurohypophysial terminal action potential broadening. J Appl Physiol (1985). 2013;115:1481-6.

27. Xu J, Yang M, Kosterin P, Salzberg BM, Milovanova TN, Bhopale VM, Thom SR. Carbon monoxide inhalation increases microparticles causing vascular and CNS dysfunction. Toxicol Appl Pharmacol. 2013;273:410-7.

28. Thom SR, Bhopale VM, Yang M. Neutrophils generate microparticles during exposure to inert gases due to cytoskeletal oxidative stress. J Biol Chem. 2014;289:18831-45.

29. Yang M, Bhopale VM, Thom SR. Ascorbic acid abrogates microparticle generation and vascular injuries associated with high-pressure exposure. J Appl Physiol (1985). 2015;119:77-82.

30. Bhullar J, Bhopale VM, Yang M, Sethuraman K, Thom SR. Microparticle formation by platelets exposed to high gas pressures - an oxidative stress response. Free Radic Biol Med. 2016;101:154-62.

31. Loane DJ, Stoica BA, Tchantchou F, Kumar A, Barrett JP, Akintola T, Xue F, Conn PJ, Faden Al. Novel mGluR5 positive allosteric modulator improves functional recovery, attenuates neurodegeneration, and alters microglial polarization after experimental traumatic brain injury. Neurotherapeutics. 2014;11:857-69.

32. Kumar A, Barrett JP, Alvarez-Croda DM, Stoica BA, Faden Al, Loane DJ. NOX2 drives M1-like microglial/macrophage activation and neurodegeneration following experimental traumatic brain injury. Brain Behav Immun. 2016;58:291-309.

33. Kabadi SV, Stoica BA, Loane DJ, Byrnes KR, Hanscom M, Cabatbat RM, Tan MT, Faden Al. Cyclin D1 gene ablation confers neuroprotection in traumatic brain injury. J Neurotrauma. 2012;29:813-27.

34. Porro C, Di Gioia S, Trotta T, Lepore S, Panaro MA, Battaglino A, Ratclif L, Castellani S, Bufo P, Martinez MC, Conese M. Pro-inflammatory effect of cystic fibrosis sputum microparticles in the murine lung. J Cyst Fibros. 2013;12:721-8.
35. Loane DJ, Kumar A. Microglia in the TBI brain: the good, the bad, and the dysregulated. Exp Neurol. 2016;275(Pt 3):316-27.

36. Tkach $\mathrm{M}$, Thery C. Communication by extracellular vesicles: where we are and where we need to go. Cell. 2016;164:1226-32.

37. Valadi H, Ekstrom K, Bossios A, Sjostrand M, Lee JJ, Lotvall JO. Exosomemediated transfer of mRNAs and microRNAs is a novel mechanism of genetic exchange between cells. Nat Cell Biol. 2007;9:654-9.

38. Takeshita J, Mohler ER, Krishnamoorthy P, Moore J, Rogers WT, Zhang L, Gelfand JM, Mehta NN. Endothelial cell-, platelet-, and monocyte/ macrophage-derived microparticles are elevated in psoriasis beyond cardiometabolic risk factors. J Am Heart Assoc. 2014;3:e000507.

39. Nie DM, Wu QL, Zheng P, Chen P, Zhang R, Li BB, Fang J, Xia LH, Hong M. Endothelial microparticles carrying hedgehog-interacting protein induce continuous endothelial damage in the pathogenesis of acute graft-versushost disease. Am J Physiol Cell Physiol. 2016;310:C821-835.

40. Gachet C. P2Y(12) receptors in platelets and other hematopoietic and nonhematopoietic cells. Purinergic Signal. 2012:8:609-19.

41. French SL, Paramitha AC, Moon MJ, Dickins RA, Hamilton JR. Humanizing the protease-activated receptor (PAR) expression profile in mouse platelets by knocking PAR1 into the Par3 locus reveals PAR1 expression is not tolerated in mouse platelets. PLoS One. 2016:11:e0165565.

42. Chan HC, Ke LY, Chu CS, Lee AS, Shen MY, Cruz MA, Hsu JF, Cheng KH, Chan HC, Lu J, et al. Highly electronegative LDL from patients with STelevation myocardial infarction triggers platelet activation and aggregation. Blood. 2013;122:3632-41.

43. Bianco F, Pravettoni E, Colombo A, Schenk U, Moller T, Matteoli M, Verderio C. Astrocyte-derived ATP induces vesicle shedding and IL-1 beta release from microglia. J Immunol. 2005;174:7268-77.

44. Qu Y, Ramachandra L, Mohr S, Franchi L, Harding CV, Nunez G, Dubyak GR. $\mathrm{P} 2 \mathrm{X} 7$ receptor-stimulated secretion of $\mathrm{MHC}$ class $\|$-containing exosomes requires the ASC/NLRP3 inflammasome but is independent of caspase-1. J Immunol. 2009;182:5052-62.

45. Loane DJ, Stoica BA, Byrnes KR, Jeong W, Faden Al. Activation of mGluR5 and inhibition of NADPH oxidase improves functional recovery after traumatic brain injury. J Neurotrauma. 2013;30:403-12.

46. Stoica BA, Loane DJ, Zhao Z, Kabadi SV, Hanscom M, Byrnes KR, Faden Al. PARP-1 inhibition attenuates neuronal loss, microglia activation and neurologica deficits after traumatic brain injury. J Neurotrauma. 2014;31:758-72.

47. Mackenzie A, Wilson HL, Kiss-Toth E, Dower SK, North RA, Surprenant A. Rapid secretion of interleukin-1 beta by microvesicle shedding. Immunity. 2001;15:825-35.

48. Mulcahy LA, Pink RC, Carter DR. Routes and mechanisms of extracellular vesicle uptake. J Extracell Vesicles. 2014;3. doi:10.3402/jev.v3.24641. ecollection 2014.

49. Fabbri M, Paone A, Calore F, Galli R, Gaudio E, Santhanam R, Lovat F, Fadda P, Mao C, Nuovo GJ, et al. MicroRNAs bind to Toll-like receptors to induce prometastatic inflammatory response. Proc Natl Acad Sci U S A. 2012;109: E2110-2116.

50. Rozmyslowicz T, Majka M, Kijowski J, Murphy SL, Conover DO, Poncz M, Ratajczak J, Gaulton GN, Ratajczak MZ. Platelet- and megakaryocyte-derived microparticles transfer CXCR4 receptor to CXCR4-null cells and make them susceptible to infection by X4-HIV. Aids. 2003;17:33-42.

51. Mack M, Kleinschmidt A, Bruhl H, Klier C, Nelson PJ, Cihak J, Plachy J, Stangassinger M, Erfle V, Schlondorff D. Transfer of the chemokine receptor CCR5 between cells by membrane-derived microparticles: a mechanism for cellular human immunodeficiency virus 1 infection. Nat Med. 2000;6:769-75.

52. Mause SF, Ritzel E, Liehn EA, Hristov M, Bidzhekov K, Muller-Newen G, Soehnlein O, Weber C. Platelet microparticles enhance the vasoregenerative potential of angiogenic early outgrowth cells after vascular injury. Circulation. 2010:122:495-506.

53. Harrison EB, Hochfelder CG, Lamberty BG, Meays BM, Morsey BM, Kelso ML, Fox HS, Yelamanchili SV. Traumatic brain injury increases levels of miR-21 in extracellular vesicles: implications for neuroinflammation. FEBS Open Bio. 2016:6:835-46.

54. Su W, Aloi MS, Garden GA. MicroRNAs mediating CNS inflammation: small regulators with powerful potential. Brain Behav Immun. 2016;52:1-8.

55. Moore CS, Rao VT, Durafourt BA, Bedell BJ, Ludwin SK, Bar-Or A, Antel JP. miR-155 as a multiple sclerosis-relevant regulator of myeloid cell polarization. Ann Neurol. 2013;74:709-20.

56. Butovsky O, Jedrychowski MP, Cialic R, Krasemann S, Murugaiyan G, Fanek Z, Greco DJ, Wu PM, Doykan CE, Kiner O, et al. Targeting miR-155 restores 
abnormal microglia and attenuates disease in SOD1 mice. Ann Neurol. 2015;77:75-99.

57. Thome AD, Harms AS, Volpicelli-Daley LA, Standaert DG. microRNA-155 regulates alpha-synuclein-induced inflammatory responses in models of Parkinson disease. J Neurosci. 2016;36:2383-90.

58. Pena-Philippides JC, Caballero-Garrido E, Lordkipanidze T, Roitbak T. In vivo inhibition of miR-155 significantly alters post-stroke inflammatory response. J Neuroinflammation. 2016;13:287.

59. Zhang Y, Mei H, Chang X, Chen F, Zhu Y, Han X. Adipocyte-derived microvesicles from obese mice induce $M 1$ macrophage phenotype through secreted miR-155. J Mol Cell Biol. 2016;8:505-17.

60. Verderio C, Muzio L, Turola E, Bergami A, Novellino L, Ruffini F, Riganti L, Corradini I, Francolini M, Garzetti L, et al. Myeloid microvesicles are a marker and therapeutic target for neuroinflammation. Ann Neurol. 2012;72:610-24.

61. Perez-Pujol S, Marker PH, Key NS. Platelet microparticles are heterogeneous and highly dependent on the activation mechanism: studies using a new digital flow cytometer. Cytometry A. 2007:71:38-45.

62. Dragovic RA, Gardiner C, Brooks AS, Tannetta DS, Ferguson DJ, Hole P, Carr B, Redman CW, Harris AL, Dobson PJ, et al. Sizing and phenotyping of cellular vesicles using nanoparticle tracking analysis. Nanomedicine. 2011;7:780-8.

63. Lawrie AS, Albanyan A, Cardigan RA, Mackie IJ, Harrison P. Microparticle sizing by dynamic light scattering in fresh-frozen plasma. Vox Sang. 2009;96:206-12

64. Oosthuyzen W, Sime NE, Ivy JR, Turtle EJ, Street JM, Pound J, Bath LE, Webb DJ, Gregory CD, Bailey MA, Dear JW. Quantification of human urinary exosomes by nanoparticle tracking analysis. J Physiol. 2013;591:5833-42.

\section{Submit your next manuscript to BioMed Central} and we will help you at every step:

- We accept pre-submission inquiries

- Our selector tool helps you to find the most relevant journal

- We provide round the clock customer support

- Convenient online submission

- Thorough peer review

- Inclusion in PubMed and all major indexing services

- Maximum visibility for your research

Submit your manuscript at www.biomedcentral.com/submit 